\title{
5 Research Square

\section{Synthetic Repurposing of Drugs in Hypertension: a Datamining Method Based on Association Rules and a Novel Discrete Algorithm}

\section{Yosef Masoudi-Sobhanzadeh}

University of Tehran

\author{
Ali Masoudi-Nejad ( $\nabla$ amasoudin@ut.ac.ir) \\ https://orcid.org/0000-0003-0659-5183
}

\section{Methodology article}

Keywords: Data mining, Drug repurposing, Hypertension, Optimization algorithm, Synthetic repurposing

Posted Date: May 11th, 2020

DOI: https://doi.org/10.21203/rs.3.rs-25124/v1

License: (c) (i) This work is licensed under a Creative Commons Attribution 4.0 International License.

Read Full License

Version of Record: A version of this preprint was published on July 16th, 2020. See the published version at https://doi.org/10.1186/s12859-020-03644-w. 


\title{
Synthetic Repurposing of Drugs in Hypertension: a
}

\section{Datamining Method Based on Association Rules}

\author{
and a Novel Discrete Algorithm
}

\section{Yosef Masoudi-Sobhanzadeh ${ }^{1, a}$, Ali Masoudi-Nejad ${ }^{1, *}$}

1. Laboratory of Systems Biology and Bioinformatics (LBB), Institute of Biochemistry and Biophysics, University of Tehran, Tehran, Iran

a masoudi.sobhanzad@ut.ac.ir

*Corresponding Author

Ali Masoudi-Nejad, Ph.D,

Laboratory of Systems Biology and Bioinformatics (LBB)

Institute of Biochemistry and Biophysics

University of Tehran, Tehran, Iran.

E-mail: $\underline{\text { amasoudin@ut.ac.ir }}$

WWW: http://LBB.ut.ac.ir 


\section{Abstract}

Background: Drug repurposing aims to detect the new benefits of the existing drugs and to reduce the spent time and cost of the drug development projects. Although synthetic repurposing of drugs may be more useful than single repurposing in terms of reducing toxicity and enhancing efficacy, the researchers have not taken it into account. To address the issue, a novel datamining method is introduced and applied to the repositioning of drugs in hypertension $(\mathrm{HT})$, which is a serious medical condition and therefore needs to be dealt with effectively through making some improved treatment plans to help cure it.

Results: a novel two-step data mining method, which is based on the If-Then association rules and a novel discrete optimization algorithm, is proposed and applied to the synthetic repurposing of drugs in $\mathrm{HT}$. The required data are extracted from DruhBank, KEGG, and DrugR+ databases. The outcomes presented that the proposed method outperforms the other state-of-the-art approaches in terms of different statistical criteria. In contrast to the previously proposed methods which failed to discover a list for some datasets, our method managed to suggest a combination of drugs for all the datasets.

Conclusion: The proposed synthetic method may revive some failed drug development projects and be a suitable plan for curing orphan and rare diseases due to using a low dosage of medicines. It is also essential to use efficient computational methods to produce better results.

Keywords: Data mining; Drug repurposing; Hypertension; Optimization algorithm; Synthetic repurposing. 


\section{1- Background}

Hypertension (HT) is a long-term medical condition in which blood circulates anomalously through the vessels. Based on the nature of the $\mathrm{HT}$, the patients are divided in two groups which are as follows [1]:

i) The primary $\mathrm{HT}$ : the genetic factors and lifestyles such as salty diet, smoking, drinking alcohol, stress, overweight, etc. [2] have an important role in inducing the HT. More than $90 \%$ of the HT patients who are mostly adults, are placed in this category.

ii) The secondary HT: some illnesses such as chronic kidney diseases can also give rise to HT [3]. Less than $10 \%$ of patients, whose HT may be reduced by treating the main illness [4], are placed in this group.

According to the world health organization, about 1.3 billion people around the world suffer from HT, which is a remarkable number [5]. Most of these patients are from the low and middle-paid countries [6] and need some proper therapeutic plans with maximum efficacy such as drug repurposing [7]. Drug repurposing or drug repositioning, which may be a suitable option to treat the disease, brings about big advantages. First, it makes the HT drug development a cost-effective and time-saving process. Second, it may be useful in curing orphan and rare HT diseases for which developing new molecular entities for them is not affordable for drug companies. Third, it is may be proved that the existing drugs have many practical applications in comparison to their previous usages.

Besides gaining drug repurposing advantages, synthetic repurposing, in which a combination of two or more drugs are prescribed instead of a specific drug, may bring various benefits as follows: 
i) It may lessen the medicines' toxicity through lowering their dosages [8]. Hence, the results can revive the drug development projects which have failed due to some biological issues such as bioavailability and not controlling large amounts of toxicity.

ii) It may enhance the efficacy of drugs and yield better treatment methods. A proper combination of drugs can produce a synergic effect and control diseases better than single therapy. However, drug-drug adverse reactions are the main challenge in front of researchers [9].

iii) It may pave the way for the new research branch on the drug repurposing and develop drug usages for a wide range of diseases [10]. Meanwhile, pharmaceutical sciences can play a critical role in determining the dosage of drugs and their technical issues.

iv) The outcomes of the proposed method may also be used for combination therapy in which some drugs can enhance the efficacy of one particular drug when combined with it [11]. The main difference between the synthetic treatment and combination therapy is that the first one uses a synthesis of drugs instead of a given medication, whereas the second one combines or more medications with a given prescription [12].

The present study aims to introduce the synthetic repurposing of drugs as a useful tool to treat various diseases such as HT. For this purpose, a novel datamining method, which is based on our proposed algorithm, is presented. The approach employed to conduct the research, consists of two main parts. First, If-Then association rules are applied to a large volume of data to extract information about drug-target interactions, drug-drug adverse reactions, and drug-diseases data are extracted. Second, the discrete version of the proposed discrete algorithm (Trader) [13] is introduced and used to discover synthetic lists that may be useful in managing $\mathrm{HT}$. 
In this study, the literature works which are associated with repurposing of drugs, are investigated and categorized from a computational perspective. The existing works are put into several groups which are as follows:

i) Machine learning-based researches: these methods explore the existing data and try to discover the relationship between inputs and outputs [14]. Overall, three types of machine learning methods, including supervised, semi-supervised, and unsupervised techniques have been used in the scope of drug discovery [15]. Also, it has been shown that some modified and improved versions of the present approaches such as deep neural networks can yield better predictive models [16]. Overfitting and insufficient amounts of data are the main challenges in generating an appropriate predictive model $[17,18]$.

ii) Mathematical theory-based researches: based on numerical and experimental experiences, researchers formulate the relationship between biological entities [19]. For instance, different mathematical equations have been proposed for calculating the structural similarity between drugs $[20,21]$ and based on the similarity score, the role of analogous drugs in treating diseases has been inspected [22]. The fact that drugs with similar structures (score), may be replaced with one another is of the utmost importance. However, it has been reported that these methods are not applicable to most projects and to qualify, they need to meet some other criteria [23].

iii) Graph and network theory-based researches: these approaches represents communication among the biological components through a graph or a network [24]. For this purpose, graph algorithms are applied to the generated system $[25,26]$, and hidden interactions are detected [27]. Although these techniques are confronted with minimal 
validity challenges and produce significant results, they are not applicable to most drug repurposing cases because biological elements follow the hypergraph theory $[28,29]$.

iv) Text mining-based researches: to gather the desired data, these methods delve into a massive volume of raw data using different algorithms [30]. The prevalent drug repositioning strategies employed for applying this approach are as follows: K-means, KNN, the association rules, and genetic algorithms [31, 32]. For best results, it is essential to organize the data effectively and apply the state-of-the-art algorithms. Our proposed approach, which employs the association rules (If-Then) [33] and a novel discrete algorithm (Trader), fits into this category of the related works.

v) Ensemble method-based researches: these approaches combine various techniques in several different ways [34], with the result that an efficient tool for predicting and discovering the hidden benefits of drugs can be generated [35]. For example, some of the related works have mixed different aspects of the computational methods and have obtained a suitable predictive model [36, 37]. From a biological perspective, it has been shown that simple techniques are sometimes better than the complex ones [38]. In general, ensemble methods strongly incline to the existing data and are rapidly overfitted.

\section{2- Results}

The proposed method for the synthetic repurposing of drugs was implemented in the MATLAB programming language and was compared with four state-of-the-art algorithms including discrete symbiotic optimization search (DSOS) [39], forest optimization algorithm (FOA) [40], world competitive contests algorithm (WCC) [41], and cuckoo optimization (CUK) algorithm [42]. 
Next, the above-mentioned state-of-the-art algorithms were applied to the generated datasets which have been described in Table 1. The selected drugs which belong to the different groups of treatment methods, are used to control HT. Three main information exist, for every drug, which are as follows: i) the total number of a drug's targets consisting of main targets and side effects, ii) the total number of a drug's targets which are effective in controlling hypertension, and (iii) the total number of drugs which have a target in common with one of the main targets of the specified drug. For instance, Nicardipine interacts with 15 targets from which only 4 targets play a key role in curing hypertension, and the remaining 11 targets are regarded as just side effects. There are also 40 drugs which interact at least interaction with the main targets of Nicardipine. Our main goal is to substitute a specified drug such as Nicardipine for an optimal subset of drugs which can control hypertension.

The outcomes obtained from applying the algorithms to the datasets have been divided into two categories, as follows:

i) In the first class of evaluations, the performance of the algorithms is examined in terms of convergence, stability, and some statistical criteria such as the P-value, the standard deviation (STD), etc. Due to the stochastic operations of the optimization algorithms, they generate various results in their different runs. For this reason, the algorithms were individually executed 50 times, and then, the generated data were analyzed. All the algorithms were executed under similar circumstances and invoked the same number of the score functions. Fig. 1 represents the convergence of the algorithms on the generated datasets, which are associated with the selected drugs. The horizontal and vertical axes show the iteration number and the best-obtained 
score, respectively. When the size of the problem or the candidate drugs is small, most of the algorithms can choose the best possible subset of medicines to cure HT. However, their performance and convergence are reduced when the total number of the candidate drugs rises, which in turn can result in their failure to acquire the best answer to the synthetic repurposing of drugs. For instance, Although the FOA algorithm has acquired the best solution to the Trandolapril dataset, it does not produce the best synthetic medicines on the remaining datasets and therefore falls into the local optima solutions.

The principles of the meta-heuristic algorithms are approximately the same. For example, these algorithms generate some random potential answers to a problem and, then, try to improve them based on some random-based operations [43]. Therefore, they must be executed at least 30 times, and their performances should be evaluated based on the produced data [44]. An algorithm, which yields very similar results in disparate runs, is more stable than the others and consequently, its generated outcomes should be better than the other ones. Fig. 2 demonstrates the algorithms' stability on the created datasets in 50 distinct executions.

The horizontal and vertical axes indicate the execution number and the best CS's score, respectively. All the algorithms have produced the best possible results on the Trandolapril in all their executions; and the generated results overlap. The stability of each algorithm will differ from that of the other ones as the candidate drugs' number increases. Overall, Trader, WCC, DSOS, FOA, and CUK, respectively are the best algorithms in terms of the stability power. 
Table 2, which shows the results of the algorithms' performance on the generated datasets in 50 distinct executions, has been provided to examine the functionality of the algorithms accurately. Table 2 presents the following information: (i) the worst results of the algorithms, (ii) the best results of the algorithms, (iii) the average value of the results, (iv) The p-value which indicates what amount of the algorithms' results is produced by chance, (v) the standard deviation (STD) of the results, and (vi) the confidence interval $(\mathrm{Cl})$ which indicates a range in which the outcomes of the algorithms are expected to be obtained. The performance of all the algorithms on the Trandolapril dataset is the same. For the Atenolol and Nicardipine datasets, the best results of the Trader and WCC algorithms are alike. The best-obtained score of the WCC algorithm on the Felodipine dataset is better than the other algorithms. In the case of the newly introduced algorithm (Trader), its best-acquired outcomes are very similar to the WCC algorithm's on the Felodipine dataset. Compared to the other algorithms, Trader has the better performance on the remaining datasets.

Table 3 summarizes the data of Table 2 and provides a comprehensive comparison between the algorithms. This Table demonstrates that compared to other methods, the newly proposed method is the more suitable option for the synthetic repositioning of drugs than others.

To make a comparison of the algorithms, their performance was examined based on the p-value [45]. For the purpose of this comparison, the results of the proposed algorithm (Trader) which were regarded as a test base, were also compared with the other algorithms' outcomes (Table 4). As mentioned earlier, the p-value of Table 2 
shows what amount of the results of the algorithms are produced randomly, but the $\mathrm{p}$-value of Table 4 demonstrates whether the proposed algorithm's performance is the same as or more efficient than the others' performance. For the purpose of comparing the proposed algorithm with an algorithm, named A, we have made a hypothesis as follow:

$\mathrm{H}_{0}$ : The performance of the proposed algorithm is the same as the performance of $\mathrm{A}$. $H_{1}$ : The performance of the proposed algorithm is more efficient than the performance of $A$.

If the $p$-value is less than $0.05, H_{0}$ will be rejected and $H_{1}$ will be accepted. Otherwise, $\mathrm{H}_{0}$ will be accepted and $\mathrm{H}_{1}$ will be rejected.

ii) In the second part of the results, the outcomes of the algorithm are discussed from the drug synthetic repurposing aspect. For every HT drug, Table 5 demonstrates a list of drugs which may be replaced with a given drug.

Trandolapril which is used for treating the minor HT, is a molecule which blocks the angiotensin-converting enzyme's activity (ACE) [46]. This medication interacts with the ACE which due to its involvement in regulating the rate of fluids in the body, can control HT. As shown in table 5, all the algorithms have proposed a drug with a few side effects, which can be replaced with Trandolapril. Atenolol, which is used to cure the abnormal rhythm of heartbeats, is a beta-blocker. Like Trandolapril, it interacts with the ACE [47]. All the algorithms have suggested a drug which can be replaced with Atenolol, as in Trandolapril's 
case. However, the proposed drugs have a number of side effects and may yield some undesired effects on a body. Trader, WCC, and DSOS managed to find some substitutes without side effects and therefore are better than FOA and CUK.

Since Carteolol acts against the beta- 2 adrenergic receptor and agonists the beta- 1 adrenergic receptor [48], the pressure of blood is reduced. For this reason, this drug can be a candidate for treating HT. All the algorithms propose a list of drugs. However, their lists and costs differ in size. Compared to the other algorithms, both Trader and WCC algorithms have obtained a proper outcome based on the score function.

Nicardipine, which is a calcium channel blocker, controls the blood pressure [49]. CUK and FOA cannot propose some candidate drugs that can be replaced with Nicardipine. WCC and DSOS have proposed only a synthetic list instead of Nicardipine, while Trader yields two lists which can be replaced with Nicardipine. According to the score function, all the lists have an identical value and maybe a suitable choice for treating HT.

Felodipine controls the pressure of blood by blocking the calcium channels and can be a proper option for curing mild and minor HT [50]. To treat HT, algorithms have proposed a pair of medications instead of Felodipine. All the medications include Pinaverium. The list suggested by Trader, has the best score value compared to the lists proposed by the other ones.

Nifedipine and Nisoldipine slow down the penetration of calcium into heart cells and vessel walls [51]. As a result, heart can pump and widen the blood vessels efficiently. 
Algorithms except Trader have failed to discover candidates which may be used instead of Nifedipine and Nisoldipine. To treat HT, Trader suggests one or two possible lists instead of Nifedipine and Nisoldipine, respectively.

Doxazosin acts against the Alpha-1A, Alpha-1B, and Alpha-1D adrenergic receptors and smooths the way for the muscle cells to grow[52]. In contrast to CUK and FOA which did not manage to detect any drug substitutes for Doxazosin, Trader, WCC, and DSOS succeeded in discovering a single-member list. In terms of quality lists, Trader, WCC, and DSOS, respectively are among the first to be functional.

Prazosin operates against the Alpha-1A, Alpha-1B, and Alpha-1D adrenergic receptors. In a comparison made among the outcomes of the algorithms, it is shown that Trader has substituted three different lists for Prazosin to control HT, whereas the other algorithms managed to replace Prazosin with just a two-member list. Moreover, from the score value viewpoint, the Trader's proposed lists are more suitable than those suggested by the other ones.

Based on the obtained results, it can be concluded that Trader (the newly proposed algorithm) is more efficient than the other state-of-the-art algorithms and proposes some better synthetic drug lists instead of the given drugs to treat HT. The results of the newly proposed drug lists by Trader have been presented in detail in Table 6. Table 6 also gives some information about the way the suggested drugs are similar; Eq. (12) has been employed to measure the amount of the existing similarity [53]: 
$\operatorname{Similarity}\left(\mathrm{D}_{\mathrm{i}}, \mathrm{D}_{\mathrm{j}}\right)=\frac{\sum_{r=1}^{n}\left(w_{r \times} C_{i, r} \times C_{j, r}\right)}{\sum_{r=1}^{n}\left(\sqrt{w_{r \times} C_{i, r}} \sqrt{w_{r \times} C_{j, r}}\right)}$

Where $D_{i}, D_{j}, n, C_{i, r}$ and $C_{j, r}$ are the $i^{\text {th }}$ drug, the $j^{\text {th }} d r u g$, the total number of the chemical components, the total number of the $\mathrm{r}^{\text {th }}$ chemical component in $\mathrm{i}^{\text {th }}$, and the total number of the $\mathrm{r}^{\text {th }}$ chemical component in the $\mathrm{j}^{\text {th }}$ chemical component, respectively. Also, $w_{r}$, which is calculated by Eq. (13), is the weight of the $r^{\text {th }}$ chemical component.

$\mathrm{W}_{\mathrm{r}}=\frac{\min \left(d_{r}, 1\right) \times \min \left(C_{i, r}, C_{j, r}\right)}{\max \left(C_{i, r}, C_{j, r}\right)+e p s}$

Where $d_{r}$ shows the data frequency of the $r^{\text {th }}$ chemical component.

\section{3- Discussion}

To discover the hidden applications of the existing drugs, a novel synthetic method based on the newly introduced discrete Trader optimization algorithm (Trader). The introduced method may reduce the toxicity of drugs and enhance their efficacy in curing diseases. To investigate the applicability of the proposed method, it was applied to the nine hypertension-related datasets, and the results were analyzed and examined from two perspectives. From the first viewpoint, it was shown that the state-of-the-art algorithms yield better various outcomes than others. The average score value and the confidence interval of the Trader were -7.79 and [-9.05 -6.52], respectively, which were remarkably better than those obtained from other algorithms. Besides, the proposed algorithm can detect some lists for all the datasets, whereas others fail. For example, except for the Trader, the other algorithms cannot explore candidates for the Nifedipine and Nisoldipine datasets. From the second viewpoint, the outcomes of the application 
of the selected drugs in the hypertension treatment were examined. A detailed examination of the data yielded some important results as follows: First, although the synthetic replacement of the drugs was not workable for all of the drugs, the proposed method succeeded in suggesting some proper substitutes for them. As mentioned before, Atenolol can interact with two targets [54], one of which is responsible for the HT, and the remaining one is a side effect. The proposed approach managed to replace Atenolol with Esmolol which belongs to a family of beta-blocker drugs and does not have any side effects [55]. The mentioned drugs may be combined with their substitutions in the lower dosages. For instance, it has been reported that a combination of Trandolapril and Cilazapril can show better efficacy in controlling HT [56]. Second, the proposed approach can introduce novel applications of some drugs. For instance, Pinaverium is a first-line option for curing bowl dysfunctionality and operates as an inhibitor and antagonist of the voltage-dependent calcium channel protein [57]. Moreover, Pinaverium used to be exploited in more than 60 countries and especially applied to cure gastrointestinal disorders. However, it did not win approval from the FDA. Based on the method employed in this research, Pinaverium may have an application in HT, which indicating that the synthetic repurposing of drugs may be the best option for reviving the drug discovery projects. The introduced approach could especially revivify the projects which had failed due to various undesired biological effects of drugs [58]. Besides, this method maybe a suitable therapy plan for treating orphans or diseases because developing an efficient drug is costly and time-consuming and therefore not affordable for drug companies[59]. Another discovered medication for managing the HT is Dapiprazole which is an alpha-blocker agent. After investigating the eye, it is possible that the pupil of it dilates [60]. To reverse the mydriasis effect, doctors prescribe Dapiprazol, which helps to reduce the size of the 
eye's pupil. Although different studies have reported many undesired side effects of Dapiprazole and other drugs such as Pinaverium [61], the proposed approach employs these drugs in an appropriate manner. To this end, the minimum dosages of the drugs are used, so the undesired effects of them are decreased [62]. Furthermore, since all the drugs were designed with the aim of achieving a common goal, a combination of medicines could have a synergic effect on curing HT [63]. In this field, although some drug-drug adverse reactions have been determined, most of them are not specified.

\section{4- Conclusion}

A novel discrete algorithm, named Trader, was introduced for the synthetic repurposing of drugs. This concept can resume most of the failed drug discovery projects and maybe the most suitable option for treating orphan and rare diseases. The proposed approach takes account of the various aspects of the synthetic repositioning of medications such as the mechanism of action of drugs on targets, drug-drug adverse reactions, and the total number of side effects. Based on the acquired outcomes, it can be concluded that the-state-of-the-art algorithms yield better results and show more suitable performance in comparison to others. Furthermore, the findings validate the functionality of the proposed method and suggest several synthetic repurposing lists to reduce the hypertension. 


\section{5- Methods}

For discovering drugs that may be useful in curing the $\mathrm{HT}$, a two-step datamining method is proposed. In the first step, according to the If-Then rules, it is determined which drugs can inhibit or prevent the targets from inducing HT. In the second step, the proposed discrete Trader optimization algorithm chooses an optimal subset of the candidate drugs whose combinations may be helpful to treat the HT. Fig. 3 presents the framework of the proposed method.

The first part of the proposed approach includes a number of steps which are as follows:

i) Obtaining data: the data related to drugs and their different targets were extracted from DrugR+ [64], which is a relational database and has integrated DrugBank [65] and KEGG [66] databases. DrugR+ database provides an online tool that accepts a drug and suggests some potential drugs that are substitute for the first one. Meanwhile, DrugR+ includes an advanced search section in which users can express their SQL queries and download the results immediately.

ii) Constituting the drug-disease (D-DI) matrix: based on the downloaded data, a binary matrix, named DDI and incorporated drugs-diseases relationships, are computed using Eq. (1).

$\mathrm{DDI}(\mathrm{i}, \mathrm{j})=\left\{\begin{array}{l}1 \text { if the } i^{\text {th }} \text { drug is used for treating the } j^{\text {th }} \text { disease } \\ 0 \text { else }\end{array}\right.$

Where $\mathrm{i}$ and $\mathrm{j}$ indicate a drug and a disease, respectively. The total number of drugs and diseases are 13,251 and 3,318, respectively. 
iii) Constituting the drug-target (D-T) matrix: this matrix shows whether a drug affects a target or not. The extracted data show that there are four classes of drug-target effects, including (a) agonizing, (b) antagonizing, (c) inhibiting, and (d) inducing. The targets whose total numbers are 4893 , consist of both proteins and enzymes. The DT matrix is computed using Eq. (2).

$\mathrm{DT}(\mathrm{i}, \mathrm{j})=\left\{\begin{array}{cl}\text { INH } & \text { if the } i^{\text {th }} \text { drug inhibits the } j^{\text {th }} \text { target } \\ \text { IND } & \text { if the } i^{\text {th }} \text { drug induces the } j^{\text {th }} \text { target } \\ A G O & \text { if the } i^{\text {th }} \text { drug agonists the } j^{\text {th }} \text { target } \\ A N T & \text { if the } i^{\text {th }} \text { drug antagonists the } j^{\text {th }} \text { target } \\ 0 & \text { else }\end{array}\right.$

iv) Constituting the drug-drug adverse reaction (DDAR) matrix: Some drugs may interact with together and neutralize their effects and bringing about serious a body. A matrix, named DDAR, is formed to investigate the problem (Eq. (3)).

$\operatorname{DDAR}(\mathrm{i}, \mathrm{j})= \begin{cases}1 & \text { if the } i^{\text {th }} \text { drug has adverse reaction with the } j^{\text {th }} \text { drug } \\ 0 & \text { else }\end{cases}$

v) Mining: during every stage of the process, we employ the DT and DDI matrices to extract some information which will be used as the input of the discrete optimization algorithm (Trader). In the first part of the proposed method, different targets related to blood pressure along with their effects (inhibiting, inducing, agonizing, and antagonizing) are determined and placed in a set named HT_TARGETS. Eq. (4) presents the mentioned set: 
$H T_{-} T A R G E T S=\left[\left(T_{1}, R_{1}\right), \ldots,\left(T_{n}, R_{n}\right)\right]$

Where $n, T_{i}$, and $R_{i}$ are the total number of the obtained targets, the $i^{\text {th }}$ target, and the effect which leads to high blood pressure disease, respectively.

Furthermore, another set, named DRUGS, is created for drugs that directly interact with the HT_TARGETS collection and exert exactly the same impact on the targets. For instance, both Angiotensin // and Candesartan drugs interact with the Type-1 angiotensin // receptor. However, Angiotensin // affects the mentioned target as agonist whereas Candesartan affects it as an antagonist. Therefore, Angiotensin I/ is ignored because its function is not exactly the same as Candesartan.

In this study, the interaction between a drug such as $D$ and a target such as $T$ (protein $(P)$ and an enzyme (E)) is presented by " $\rightarrow$ ". The effect of $D$ on $T$ and the cause of blood pressure due to the defects in T are shown by $F(D, T)$ and $F(H T, T)$, respectively. Next, the following rules are applied to all the existing drugs, and the candidate drugs are also added to the DRUGS set.

a) IF D $\rightarrow$ T \& \& F(D,T) $=F(H T, T)$ THEN

D may be useful for controlling HT

b) IF E $\rightarrow$ P \&\& F(E,P) $=F(H T, P)$ THEN

The drug, which interacts with E, may be useful for controlling HT

c) IF P $\rightarrow E \& \& F(E, P)=F(H T, E)$ THEN

The drug, which interacts with $\mathrm{P}$, may be useful for controlling HT

d) IF $P_{1} \rightarrow P_{2} \& \& F\left(P_{1}, P_{2}\right)=F\left(H T, P_{2}\right)$ THEN 
The drug, which interacts with $\mathrm{P}_{1}$, may be useful for controlling HT

e) IF $E_{1} \rightarrow E_{2} \& \& F\left(E_{1}, E_{2}\right)=F\left(H T, E_{2}\right)$ THEN

The drug, which interacts with $E_{1}$, may be useful for controlling HT

In the second part of the proposed method, the discrete Trader optimization algorithm is applied to select the optimal subsets of the obtained drugs, which may reduce the pressure of blood. For this purpose, a number of steps are followed:

i) Creating the first population of the candidate solutions (CSs): Trader begins with a randomly created potential answers, which are presented by an array shown in Eq. (5).

$\mathrm{CS}=\left[\mathrm{V}_{1}, \mathrm{~V}_{2}, \ldots, \mathrm{V}_{\mathrm{m}}, \mathrm{G}, \mathrm{Score}\right]$

Where $\mathrm{V}_{\mathrm{i}}, \mathrm{m}, \mathrm{G}$, and Score are the $\mathrm{i}^{\text {th }}$ variable, the total number of variables, the group, and the score or fitness of the CS. Every variable shows a drug and its value is set 1 or 0 value for the selected and unselected drug, respectively.

ii) Calculating the score of the CSs: The CSs are answers to the mentioned problem, and they differ widely in terms of how much they are worthy of consideration. In this study, the score is calculated using Eq. (6).

Score $=A T-\frac{\sum_{i=}^{m} S E_{i}}{\sum_{i=1}^{m} v_{i}}$ 
Where $\mathrm{m}, \mathrm{v}_{\mathrm{i}}, \mathrm{SE}$, and AT represent the length of a CS, the value of the $\mathrm{i}^{\text {th }}$ variable $(0$ or 1), the total number of side effects related to the $\mathrm{i}^{\text {th }} \mathrm{drug}$, and the total number of the covered targets correspondent with HT, respectively.

iii) Grouping CSs: The total number of groups and the total number of traders are the same, and a trader shows a group. At the beginning of the algorithm, the total number of members in the groups is the same. In the next iterations, the total number of members in a group is calculated using Eq. (7).

$\mathrm{TM}_{\mathrm{i}}=\operatorname{round}\left(\frac{\text { property }_{i}}{\sum_{k=1}^{T} \text { property }_{k}} \times(\mathrm{C}-\mathrm{M} \times \mathrm{T})\right)$

Where $\mathrm{TM}_{\mathrm{i}}, \mathrm{C}$, and $\mathrm{T}$ present the total number of members in the $\mathrm{i}^{\text {th }}$ group, the total number of CSs, and the total number of traders or groups, respectively. $M$ is a constant value (2) and guarantees that none of the groups will be eliminated during the iterations of the algorithm in each stage. As shown in Eq. (8), property of the $\mathrm{i}^{\text {th }}$ trader.

property $_{i}=\sum_{i=1}^{M} \operatorname{score}\left(C S_{i}\right)$

Where $\mathrm{M}$ and score show the total number of CSs in the $\mathrm{i}^{\text {th }}$ group and the score of the related CS, respectively. In other words, the property of a group is equivalent to the sum of its CSs' scores. 
iv) Changing the CSs: there are three operators, who change the master and slave CSs. As shown in Eqs. $(9,10$, and 11), these operators, named retailing, distributing, and importing-exporting, try to improve the CSs. when the retailing operator is employed, the minimum number of changes will be applied to a slave-CS. The distributing operator obtains some values from the best of the group (the master-CS) and then, assigns them to a CS. While both the distributing and retailing operators change the slave-CSs, the importing-exporting operator brings about changes in the master-CSs. The changes can be accepted in all of the operators, provided that they improve the value of a CS's score.

$\sum_{i=1}^{R}\left(C S \_s l a v e(K)=\operatorname{abs}\left(C S \_s l a v e(K)-1\right)\right)$

Where $K$ and $R$ are two random integer values in [1, length(CS)] and [1, length(CS)/10], respectively.

$\sum_{i=1}^{R}\left(C S \_\right.$slave $(K)=C S \_$master $\left.(K)\right)$

Where $\mathrm{K}$ and $\mathrm{R}$ are two random integer values in [1, length(CS)].

$\sum_{i=1}^{R}\left(C S \_\operatorname{master}_{j}(K)=\right.$ CS_master $\left._{m}(K)\right)$ 
Where $\mathrm{j}$ and $\mathrm{m}$ are the importer and exporter CSs, respectively. Also, the values of $\mathrm{K}$ and $\mathrm{R}$ can be measured using Eq. (9).

The application of the mentioned operators to the CSs is illustrated in Fig. 4.

\author{
Abbreviations \\ ACE: Angiotensin-Converting Enzyme \\ ATE: Atenolol \\ CAR: Carteolol \\ $\mathrm{Cl}$ : Confidence Interval \\ CS: Candidate Solution \\ CUK: cuckoo optimization \\ D-DI: Drug-Disease \\ D-T: Drug-Target \\ DDR: drug-drug adverse reaction \\ DOX: Doxazosin \\ DSOS: discrete symbiotic optimization search \\ FEL: Felodipine \\ FOA: forest optimization algorithm \\ HT: Hypertension \\ NIC: Nicardipine \\ NIF: Nifedipine \\ NIS: Nisoldipine \\ PAR Prazosin \\ STD: Standard Deviation
}


TNC: Total number of candidates

TNMT: total number of main targets

TNT: total number of targets

TRA: Trandolapril

WCC: world competitive contests

\section{Declaration}

Ethics approval and consent to participate

Not Applicable.

\section{Consent for publication}

All authors gave consent for publication.

\section{Availability of materials and data}

All the source codes are available in the following link: https://github.com/LBBSoft/Trader

\section{Competing interests}

The authors declare that they have no competing interests.

\section{Funding}

No Funding

\section{Authors' contributions}

YMS: Conceptualization, implementation, formal analysis, investigation, writing, editing, and revising the manuscript. AM: Conceptualization, Supervision, Project administration, writing, editing, and revising the manuscript. All authors have read and approved the manuscript. 


\section{Acknowledgments}

The authors would like to appreciate Iranian National Science Founding (INSF) for their technical supports.

\section{References}

1. Kaszuba A, Konior A, Mikolajczyk T, Prejbisz A, Kabat M, Januszewicz A, Guzik T: P2629T cell subset imbalance in hypertension is not associated with angiotensin II levels in patients with primary and secondary hypertension. European Heart Journal 2017, 38(suppl_1).

2. Bigazzi R, Zagato L, Lanzani C, Fontana S, Messaggio E, Delli Carpini S, Citterio L, Simonini M, Brioni E, Magnaghi C: Hypertension in High School Students: Genetic and Environmental Factors: The HYGEF Study. Hypertension 2020:HYPERTENSIONAHA. 119.13818.

3. Johnson RJ, Bakris GL, Borghi C, Chonchol MB, Feldman D, Lanaspa MA, Merriman TR, Moe OW, Mount DB, Lozada LGS: Hyperuricemia, acute and chronic kidney disease, hypertension, and cardiovascular disease: report of a scientific workshop organized by the National Kidney Foundation. American Journal of Kidney Diseases 2018, 71(6):851-865.

4. Walker V, Davies N, Kehoe P, Martin R: Can treatments for hypertension be repurposed for the treatment of dementia? Revue d'Épidémiologie et de Santé Publique 2018, 66:S262.

5. Khouri C, Lepelley M, Roustit M, Montastruc F, Humbert M, Cracowski J-L: Comparative safety of drugs targeting the nitric oxide pathway in pulmonary hypertension: a mixed approach combining a meta-analysis of clinical trials and a disproportionality analysis from the world health organization pharmacovigilance database. Chest 2018, 154(1):136-147.

6. Zack R, Okunade O, Olson E, Salt M, Amodeo C, Anchala R, Berwanger O, Campbell N, Chia Y-C, Damasceno A: Improving Hypertension Outcome Measurement in Low-and Middle-Income Countries. Hypertension 2019, 73(5):990-997.

7. Saluja S, Jiang X, Finan C, Chopade S, Eales J, Xu X, Samani NJ, Charchar FJ, Hingorani A, Tomaszewski M: New Drug Repurposing Opportunities for Hypertension Uncovered by the Convergence of Genomics With Kidney Transcriptomics and Epigenomics. Circulation 2019, 140(Suppl_1):A14286-A14286.

8. Sun $W$, Sanderson $P E$, Zheng $W$ : Drug combination therapy increases successful drug repositioning. Drug discovery today 2016, 21(7):1189-1195.

9. Papamichael K, Cheifetz AS: Therapeutic drug monitoring in IBD: the new standard-of-care for anti-TNF therapy. The American journal of gastroenterology 2017, 112(5):673.

10. Kuenzi BM, Rix LLR, Kinose F, Kroeger JL, Lancet JE, Padron E, Rix U: Off-target based drug repurposing opportunities for tivantinib in acute myeloid leukemia. Scientific reports 2019, 9(1):606.

11. Tran KA, Cheng MY, Mitra A, Ogawa H, Shi VY, Olney LP, Kloxin AM, Maverakis E: MEK inhibitors and their potential in the treatment of advanced melanoma: the advantages of combination therapy. Drug design, development and therapy 2016, 10:43. 
12. Ullah RS, Wang L, Yu H, Haroon M, Elshaarani T, Fahad S, Khan A, Nazir A, Xia X, Teng L: Synthesis of polyphosphazene and preparation of microspheres from polyphosphazene blends with PMMA for drug combination therapy. Journal of materials science 2019, 54(1):745-764.

13. Masoudi-Sobhanzadeh Y, Omidi Y, Amanlou M, Masoudi-Nejad A: Trader as a new optimization algorithm predicts drug-target interactions efficiently. Scientific Reports 2019, 9(1):9348.

14. Ekins S, Puhl AC, Zorn KM, Lane TR, Russo DP, Klein JJ, Hickey AJ, Clark AM: Exploiting machine learning for end-to-end drug discovery and development. Nature materials 2019, 18(5):435.

15. Vamathevan J, Clark D, Czodrowski P, Dunham I, Ferran E, Lee G, Li B, Madabhushi A, Shah P, Spitzer M: Applications of machine learning in drug discovery and development. Nature Reviews Drug Discovery 2019, 18(6):463-477.

16. Abbasi K, Poso A, Ghasemi J, Amanlou M, Masoudi-Nejad A: Deep Transferable Compound Representation across Domains and Tasks for Low Data Drug Discovery. Journal of chemical information and modeling 2019, 59(11):4528-4539.

17. Peng L, Peng M, Liao B, Huang G, Li W, Xie D: The advances and challenges of deep learning application in biological big data processing. Current Bioinformatics 2018, 13(4):352-359.

18. AlQuraishi M: ProteinNet: a standardized data set for machine learning of protein structure. BMC bioinformatics 2019, 20(1):311.

19. Carrara L, Lavezzi SM, Borella E, De Nicolao G, Magni P, Poggesi I: Current mathematical models for cancer drug discovery. Expert opinion on drug discovery 2017, 12(8):785-799.

20. Wang P, Li K, Tao Y, Li D, Zhang Y, XU H, Yang H: TCM-ADMEpred: A novel strategy for polypharmacokinetics prediction of traditional Chinese medicine based on single constituent pharmacokinetics, structural similarity, and mathematical modeling. Journal of ethnopharmacology 2019, 236:277-287.

21. Sridhar D, Fakhraei S, Getoor L: A probabilistic approach for collective similarity-based drugdrug interaction prediction. Bioinformatics 2016, 32(20):3175-3182.

22. Vanhaelen Q, Mamoshina P, Aliper AM, Artemov A, Lezhnina K, Ozerov I, Labat I, Zhavoronkov A: Design of efficient computational workflows for in silico drug repurposing. Drug Discovery Today 2017, 22(2):210-222.

23. Iwata H, Sawada R, Mizutani S, Yamanishi Y: Systematic drug repositioning for a wide range of diseases with integrative analyses of phenotypic and molecular data. Journal of chemical information and modeling 2015, 55(2):446-459.

24. Cheng F, Desai RJ, Handy DE, Wang R, Schneeweiss S, Barabási A-Ls, Loscalzo J: Network-based approach to prediction and population-based validation of in silico drug repurposing. Nature communications 2018, 9(1):2691.

25. Pushpakom S, lorio F, Eyers PA, Escott KJ, Hopper S, Wells A, Doig A, Guilliams T, Latimer J, McNamee C: Drug repurposing: progress, challenges and recommendations. Nature Reviews Drug Discovery 2019, 18(1):41.

26. Motieghader H, Kouhsar M, Najafi A, Sadeghi B, Masoudi-Nejad A: mRNA-miRNA bipartite network reconstruction to predict prognostic module biomarkers in colorectal cancer stage differentiation. Molecular BioSystems 2017, 13(10):2168-2180.

27. Peng J, Hui W, Shang X: Measuring phenotype-phenotype similarity through the interactome. BMC bioinformatics 2018, 19(5):114.

28. Franzese N, Groce A, Murali T, Ritz A: Hypergraph-based connectivity measures for signaling pathway topologies. PLOS computational biology 2019, 15(10).

29. Weighill DA, Jacobson DA: 3-way networks: application of hypergraphs for modelling increased complexity in comparative genomics. PLoS computational biology 2015, 11(3):e1004079.

30. Yang H-T, Ju J-H, Wong Y-T, Shmulevich I, Chiang J-H: Literature-based discovery of new candidates for drug repurposing. Briefings in bioinformatics 2017, 18(3):488-497. 
31. Kaur R, Gangwar R: A Review on Naive Baye's (NB), J48 and K-Means Based Mining Algorithms for Medical Data Mining. Int Res J Eng Technol 2017, 4:1664-1668.

32. Gonzalez GH, Tahsin T, Goodale BC, Greene AC, Greene CS: Recent advances and emerging applications in text and data mining for biomedical discovery. Briefings in bioinformatics 2015, 17(1):33-42.

33. Hela S, Amel B, Badran R: Early anomaly detection in smart home: A causal association rulebased approach. Artificial intelligence in medicine 2018, 91:57-71.

34. Ezzat $\mathrm{A}, \mathrm{Wu} \mathrm{M}, \mathrm{Li} \mathrm{X}, \mathrm{Kwoh} \mathrm{C}-\mathrm{K}$ : Computational prediction of drug-target interactions via ensemble learning. In: Computational Methods for Drug Repurposing. Springer; 2019: 239-254.

35. Zhao Q, Yu H, Ji M, Zhao Y, Chen X: Computational model development of drug-target interaction prediction: A review. Current Protein and Peptide Science 2019, 20(6):492-494.

36. Wu G, Liu J, Yue X: Prediction of drug-disease associations based on ensemble meta paths and singular value decomposition. BMC bioinformatics 2019, 20(3):134.

37. Dovrolis N, Kolios G, Spyrou G, Maroulakou I: Laying in silico pipelines for drug repositioning: a paradigm in ensemble analysis for neurodegenerative diseases. Drug discovery today 2017, 22(5):805-813.

38. Kouhsar M, Jamalkandi SA, Moeini A, Masoudi-Nejad A: Detection of novel biomarkers for early detection of Non-Muscle-Invasive Bladder Cancer using Competing Endogenous RNA network analysis. Scientific reports 2019, 9(1):8434.

39. Ezugwu AE-S, Adewumi AO: Discrete symbiotic organisms search algorithm for travelling salesman problem. Expert Systems with Applications 2017, 87:70-78.

40. Ghaemi M, Feizi-Derakhshi M-R: Forest optimization algorithm. Expert Systems with Applications 2014, 41(15):6676-6687.

41. Masoudi-Sobhanzadeh Y, Motieghader H: World Competitive Contests (WCC) algorithm: A novel intelligent optimization algorithm for biological and non-biological problems. Informatics in Medicine Unlocked 2016, 3:15-28.

42. Rajabioun R: Cuckoo optimization algorithm. Applied soft computing 2011, 11(8):5508-5518.

43. Abdi $Y$, Feizi-Derakhshi M-R: Hybrid multi-objective evolutionary algorithm based on Search Manager framework for big data optimization problems. Applied Soft Computing 2019:105991.

44. Črepinšek $M$, Ravber M, Mernik $M$, Kosar $\mathrm{T}$ : Tuning Multi-Objective Evolutionary Algorithms on Different Sized Problem Sets. Mathematics 2019, 7(9):824.

45. Khalvati F, Zhang Y, Baig S, Lobo-Mueller EM, Karanicolas P, Gallinger S, Haider MA: Prognostic Value of CT Radiomic Features in Resectable Pancreatic Ductal Adenocarcinoma. Scientific reports 2019, 9(1):5449.

46. Davis J, Oparil S: Novel Medical Treatments for Hypertension and Related Comorbidities. Current hypertension reports 2018, 20(10):90.

47. com AMWda: Pharmacological management of stable angina pectoris aims to relieve symptoms and maximize survival. Drugs \& Therapy Perspectives 2017, 33:375-381.

48. Frishman WH: Beta-adrenergic receptor blockers in hypertension: alive and well. Progress in cardiovascular diseases 2016, 59(3):247-252.

49. Seeman T, Hamdani G, Mitsnefes M: Hypertensive crisis in children and adolescents. Pediatric Nephrology 2019, 34(12):2523-2537.

50. Braschi A: Potential protective role of blood pressure-lowering drugs on the balance between hemostasis and fibrinolysis in hypertensive patients at rest and during exercise. American Journal of Cardiovascular Drugs 2019, 19(2):133-171.

51. Wang $X$ : Therapeutic effect of nifedipine combined with enalapril on elderly patients with coronary heart disease complicated with hypertension. Journal of Clinical and Nursing Research 2018, 2(6). 
52. Waller JR, Waller DG: Drugs for systemic hypertension and angina. Medicine 2018, 46(9):566572.

53. Sawada R, Iwata $M$, Tabei $Y$, Yamato $H$, Yamanishi $Y$ : Predicting inhibitory and activatory drug targets by chemically and genetically perturbed transcriptome signatures. Scientific reports 2018, 8(1):156.

54. Ji Y, Chen S, Wang Q, Xiang B, Xu Z, Zhong L, Yang K, Lu G, Qiu L: Intolerable side effects during propranolol therapy for infantile hemangioma: frequency, risk factors and management. Scientific reports 2018, 8(1):4264.

55. Quintana-Villamandos B, Delgado-Martos MJ, Delgado-Baeza E: Early reversal cardiac with esmolol in hypertensive rats: The role of subcellular organelle phenotype. Pharmacological Reports 2019, 71(6):1125-1132.

56. Wishart DS, Feunang YD, Guo AC, Lo EJ, Marcu A, Grant JR, Sajed T, Johnson D, Li C, Sayeeda Z: DrugBank 5.0: a major update to the DrugBank database for 2018. Nucleic acids research 2017, 46(D1):D1074-D1082.

57. García-Alvarado F, Govoni G, de Pascual R, Ruiz-Ruiz C, Muñoz-Montero A, Gandía L, de Diego AM, García AG: Otilonium and pinaverium trigger mitochondrial-mediated apoptosis in rat embryo cortical neurons in vitro. Neurotoxicology 2019, 70:99-111.

58. Boeree MJ, Heinrich N, Aarnoutse R, Diacon AH, Dawson R, Rehal S, Kibiki GS, Churchyard G, Sanne I, Ntinginya NE: High-dose rifampicin, moxifloxacin, and SQ109 for treating tuberculosis: a multiarm, multi-stage randomised controlled trial. The Lancet infectious diseases 2017, 17(1):39-49.

59. Pogue RE, Cavalcanti DP, Shanker S, Andrade RV, Aguiar LR, de Carvalho JL, Costa FF: Rare genetic diseases: update on diagnosis, treatment and online resources. Drug discovery today 2018, 23(1):187-195.

60. Rai BB, Sabeti F, Carle CF, Rohan EM, Saraç Ö, van Kleef J, Maddess T: Recovery dynamics of multifocal pupillographic objective perimetry from tropicamide dilation. Graefe's Archive for Clinical and Experimental Ophthalmology 2019:1-10.

61. Azuamah Y, Esenwah E, Ikoro N, Megwas A, Ugwuoke G, Ogbonna U: Effect of Topical $\mathbf{1 \%}$ Pilocarpine on the Ocular Tear Film pH. International Journal of Research 2019, 6(7):120-128.

62. Ambasta $S$, Mahapatra $S$ : Attenuation of hypertensive response with esmolol and labetalol in low doses in orotracheal intubation: A comparative study. Indian Journal of Clinical Anaesthesia 2018, 5(2):272-276.

63. Alencar AK, Carvalho FI, Silva AM, Martinez ST, Calasans-Maia JA, Fraga CM, Barreiro EJ, ZapataSudo G, Sudo RT: Synergistic interaction between a PDE5 inhibitor (sildenafil) and a new adenosine A2A receptor agonist (LASSBio-1359) improves pulmonary hypertension in rats. PloS one 2018, 13(4):e0195047.

64. Masoudi-Sobhanzadeh $\mathrm{Y}$, Omidi $\mathrm{Y}$, Amanlou M, Masoudi-Nejad A: DrugR+: A comprehensive relational database for drug repurposing, combination therapy, and replacement therapy. Computers in biology and medicine 2019, 109:254-262.

65. Wishart DS, Knox C, Guo AC, Cheng D, Shrivastava S, Tzur D, Gautam B, Hassanali M: DrugBank: a knowledgebase for drugs, drug actions and drug targets. Nucleic acids research 2007, 36(suppl_1):D901-D906.

66. Kanehisa M, Goto S: KEGG: kyoto encyclopedia of genes and genomes. Nucleic acids research 2000, 28(1):27-30. 


\section{Figures}
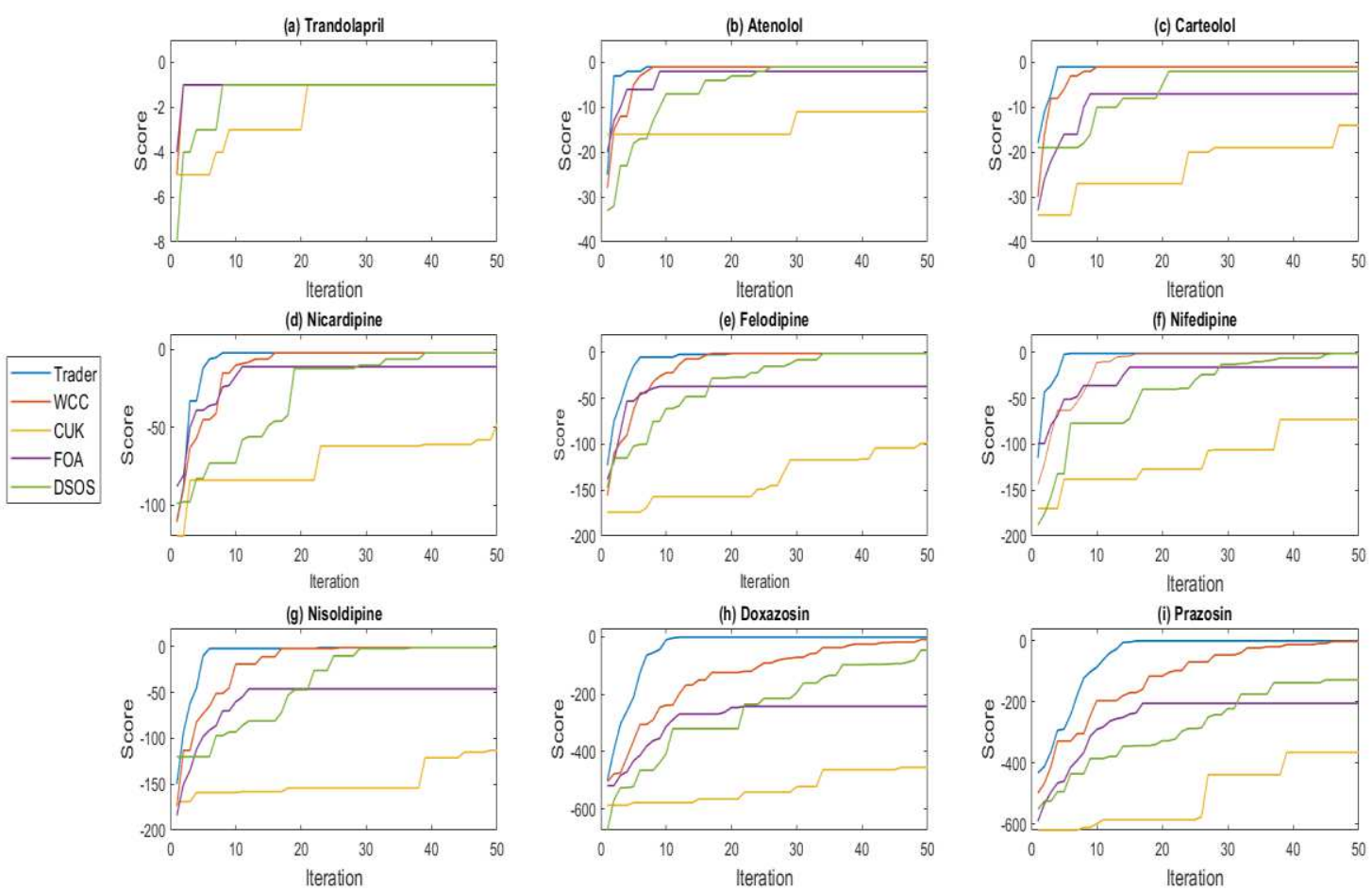

Fig. 1: The convergence behavior of the algorithms on the generated datasets. (a) The convergence of the algorithms on the Trandolapril dataset. (b) The convergence of the algorithms on the Atenolol dataset. (c) The convergence of the algorithms on the Carteolol dataset. (d) The convergence of the algorithms on the Nicardipine dataset. (e) The convergence of the algorithms on the Felodipine dataset. (f) The convergence of the algorithms on the Nifedipine dataset. (g) The convergence of the algorithms on the Nisoldipine dataset. (h) The convergence of the algorithms on the Doxazosin dataset. (i) The convergence of the algorithms on the Prazosin dataset. For the datasets with small sizes, the performance of the algorithms is almost the same. However, through increasing the total number of candidate drugs (the size of the problem), algorithms display different functionality. Trader, WCC, DSOS, FOA, and CUK, respectively are among the algorithms which are considered to have the proper convergence behavior. 

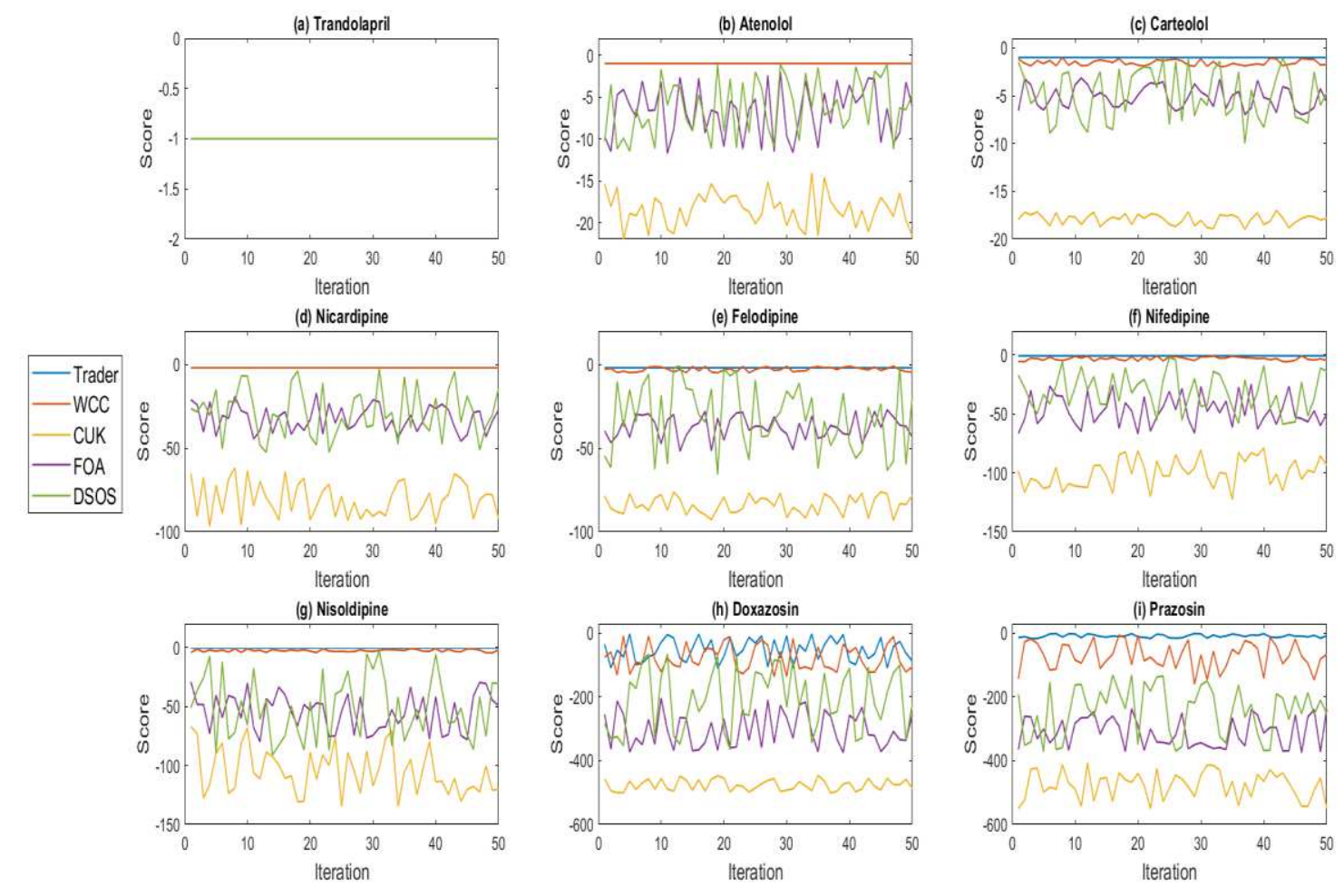

Fig. 2: The stability behavior of the algorithms on the generated dataset. (a) The stability of the algorithms on the Trandolapril dataset. (b) The stability of the algorithms on the Atenolol dataset. (c) The stability of the algorithms on the Carteolol dataset. (d) The stability of the algorithms on the Nicardipine dataset. (e) The stability of the algorithms on the Felodipine dataset. (f) The stability of the algorithms on the Nifedipine dataset. (g) The stability of the algorithms on the Nisoldipine dataset. (h) The stability of the algorithms on the Doxazosin dataset. (i) The stability of the algorithms on the Prazosin dataset. Trader is remarkably more stable than the others and delivers better results on the datasets except for Trandolapril and Nicardipine. Moreover, Trader's performance is better than the others' because the performance of the other algorithms lowers through increasing the total number of candidate drugs. 
Datamining \#1: IF-Then rules

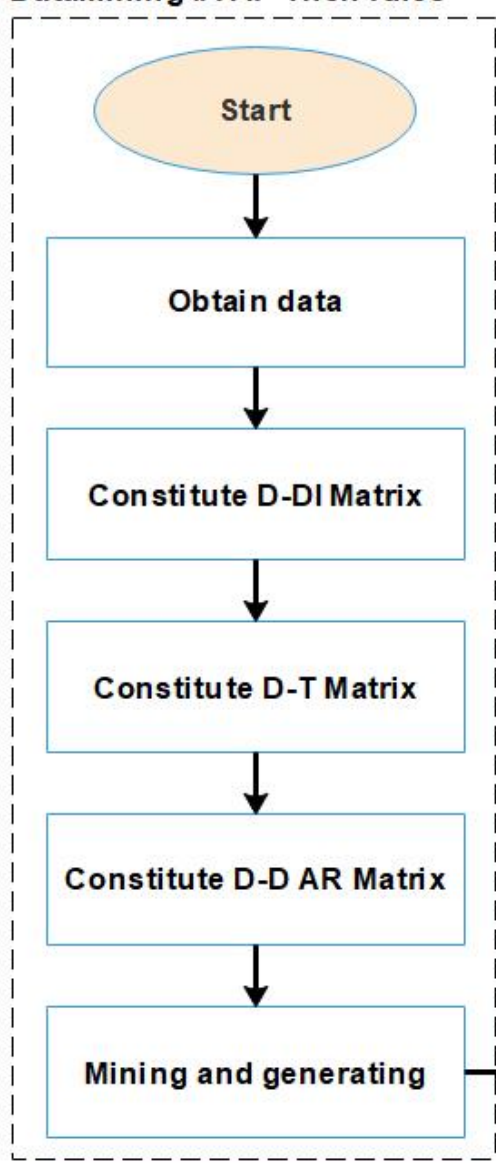

Datamining \#2: Trader Optimi zation Algorithm

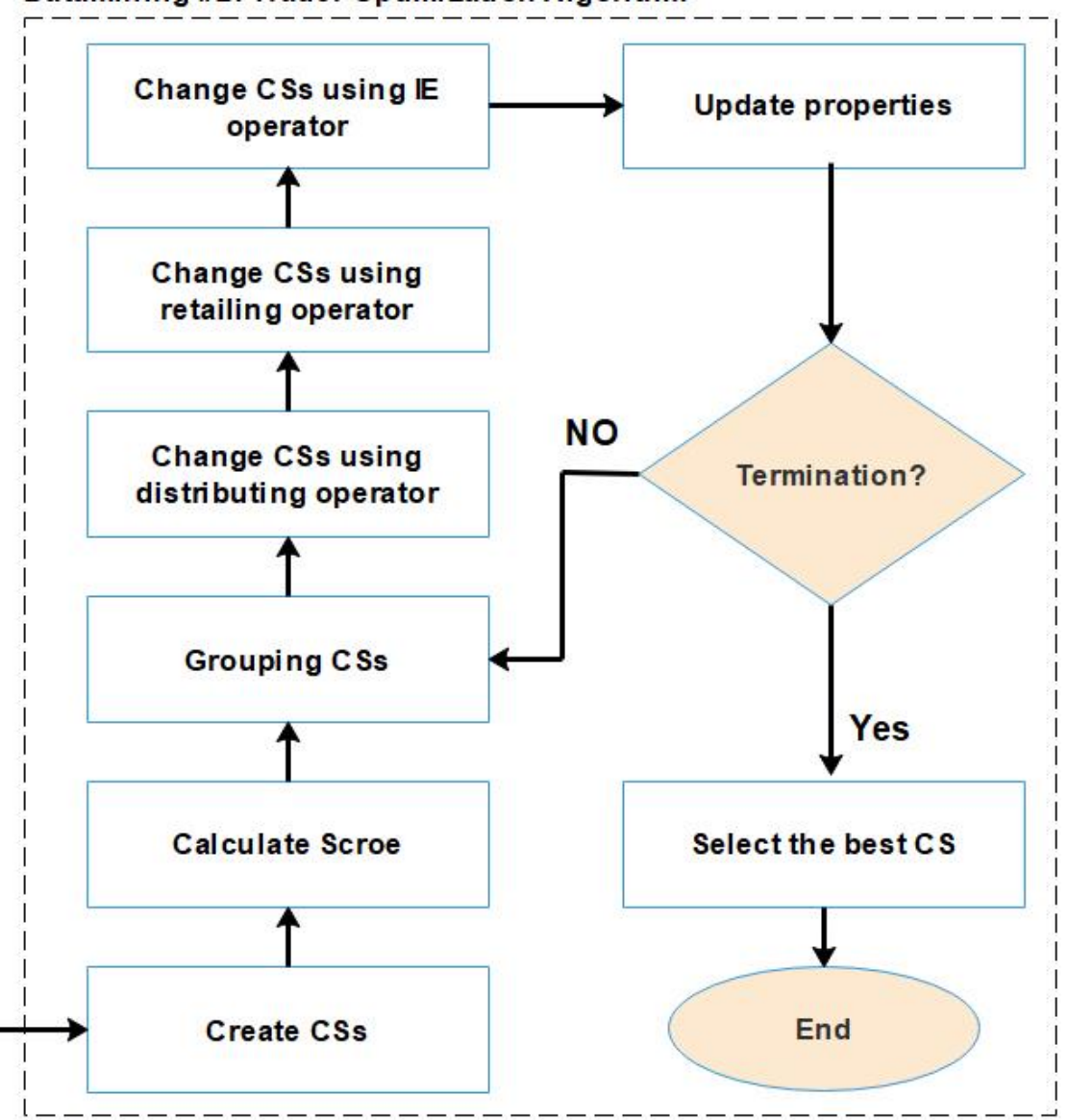

Fig. 3: The framework of the proposed method. In the first step, the desired data are obtained from DrugR+ database. Next, drug-disease (D-DI), drug-target (D-T), and drug-drug-adverse reaction (D-D AR) matrices are formed. Drugs which can affect the HT inducing targets, are acquired based on the If-then rules. In the second step, the proposed optimization algorithm (Trader) is used to select a combination of drugs for the repurposing in HT. 


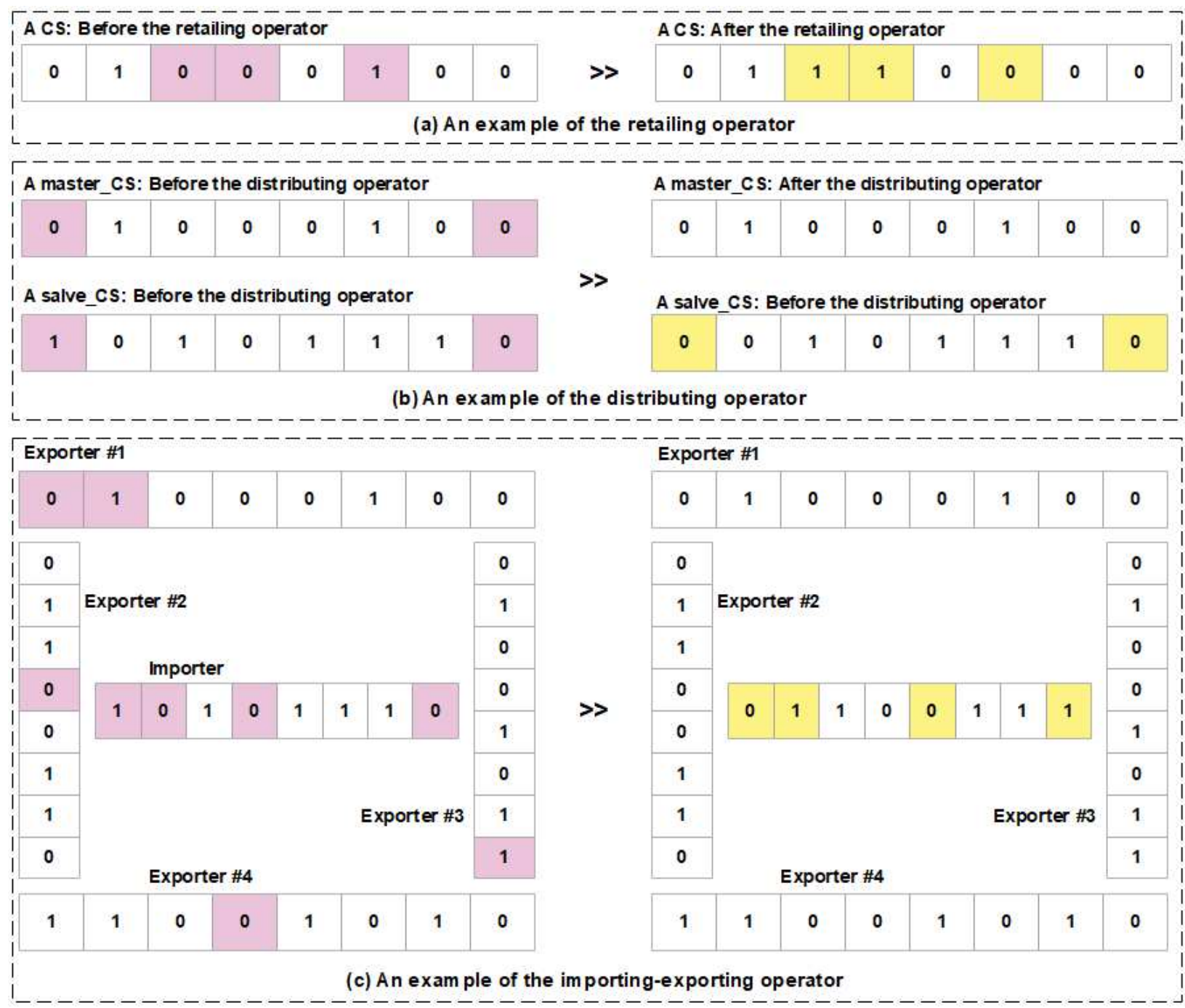

Fig. 4: The Trader's operators. (a) An example of the retailing operator: three points have been chosen randomly, and, then, their values have been updated by Eq. (9). This operator is only applied to slave_CSs. (b) An instance of the distributing operator: The master_CS selects two values from himself and distributes them to the slave_CS. (c) An example of the importingexporting operator: The exporter CSs select some of their values and send them to the importer CS. After applying the operators, the score function is called. The changes can be accepted, provided that the new score is better than the previous one. In contrast, the changes will be ignored, if the previous values are retrieved from the memory. 
Tables

Table 1. The properties of the generated datasets

\begin{tabular}{|c|c|c|c|c|c|c|}
\hline DrugBank Id & Drug name & Abbr & Chemical structure & TNT & TNMT & TNC \\
\hline DB00519 & Trandolapril & TRA & & 1 & 1 & 16 \\
\hline DB00335 & Atenolol & ATE & & 2 & 1 & 26 \\
\hline DB00521 & Carteolol & CAR & & 2 & 2 & 28 \\
\hline DB00622 & Nicardipine & NIC & & 15 & 4 & 40 \\
\hline DB01023 & Felodipine & FEL & & 13 & 5 & 50 \\
\hline DB01115 & Nifedipine & NIF & & 8 & 5 & 50 \\
\hline DB00401 & Nisoldipine & NIS & & 5 & 5 & 50 \\
\hline DB00590 & Doxazosin & DOX & & 6 & 3 & 112 \\
\hline
\end{tabular}




\begin{tabular}{|l|l|l|l|l|}
\hline $\mathrm{DB00457}$ & Prazosin & TNT: the total number of targets; TNMT: the total number of main targets; TNC: the total number of candidates. \\
\hline
\end{tabular}

Table 2. A comparison of the algorithms' performance on the generated datasets

\begin{tabular}{|c|c|c|c|c|c|c|c|c|}
\hline Dataset & Algorithm & Worst & Best & Average & STD & P-value & Low of $\mathrm{Cl}$ & High of $\mathrm{Cl}$ \\
\hline \multirow[t]{5}{*}{ TRA } & Trader & -1.00 & -1.00 & -1.00 & 0.00 & 0 & -1.00 & -1.00 \\
\hline & WCC & -1.00 & -1.00 & -1.00 & 0.00 & 0 & -1.00 & -1.00 \\
\hline & CUK & -1.00 & -1.00 & -1.00 & 0.00 & 0 & -1.00 & -1.00 \\
\hline & FOA & -1.00 & -1.00 & -1.00 & 0.00 & 0 & -1.00 & -1.00 \\
\hline & DSOS & -1.00 & -1.00 & -1.00 & 0.00 & 0 & -1.00 & -1.00 \\
\hline \multirow[t]{5}{*}{ ATE } & Trader & -1.00 & -1.00 & -1.00 & 0.00 & 0 & -1.00 & -1.00 \\
\hline & WCC & -1.00 & -1.00 & -1.00 & 0.00 & 0 & -1.00 & -1.00 \\
\hline & CUK & -21.93 & -14.03 & -18.40 & 1.98 & $2.00 \mathrm{E}-49$ & -18.96 & -17.83 \\
\hline & FOA & -11.72 & -2.01 & -6.75 & 3.02 & $7.44 \mathrm{E}-21$ & -7.61 & -5.89 \\
\hline & DSOS & -11.44 & -1.09 & -6.20 & 3.37 & $1.61 \mathrm{E}-17$ & -7.16 & $\begin{array}{l}-5.24 \\
\end{array}$ \\
\hline \multirow[t]{5}{*}{ CAR } & Trader & -1.00 & -1.00 & -1.00 & 0.00 & 0 & -1.00 & -1.00 \\
\hline & WCC & -1.99 & -1.02 & -1.55 & 0.29 & $1.40 \mathrm{E}-37$ & -1.63 & -1.47 \\
\hline & CUK & -18.97 & -17.00 & -17.90 & 0.54 & $1.49 \mathrm{E}-76$ & -18.05 & -17.74 \\
\hline & FOA & -6.98 & -3.15 & -5.18 & 1.16 & $3.31 \mathrm{E}-34$ & -5.51 & -4.85 \\
\hline & DSOS & -9.99 & -1.04 & -4.90 & 2.63 & $9.86 \mathrm{E}-18$ & -5.65 & -4.15 \\
\hline \multirow[t]{5}{*}{ NIC } & Trader & -2.00 & -2.00 & -2.00 & 0.00 & 0 & -2.00 & -2.00 \\
\hline & WCC & -2.00 & -2.00 & -2.00 & 0.00 & 0 & -2.00 & -2.00 \\
\hline & CUK & -96.80 & -61.69 & -80.69 & 10.44 & $1.39 E-45$ & -83.66 & -77.73 \\
\hline & FOA & -45.91 & -17.13 & -32.25 & 7.71 & $6.68 \mathrm{E}-33$ & -34.44 & -30.05 \\
\hline & DSOS & -52.49 & -2.20 & -28.40 & 14.57 & $1.72 \mathrm{E}-18$ & -32.54 & -24.26 \\
\hline FEL & Trader & -2.00 & -2.00 & -2.00 & 0.00 & 0 & -2.00 & -2.00 \\
\hline
\end{tabular}




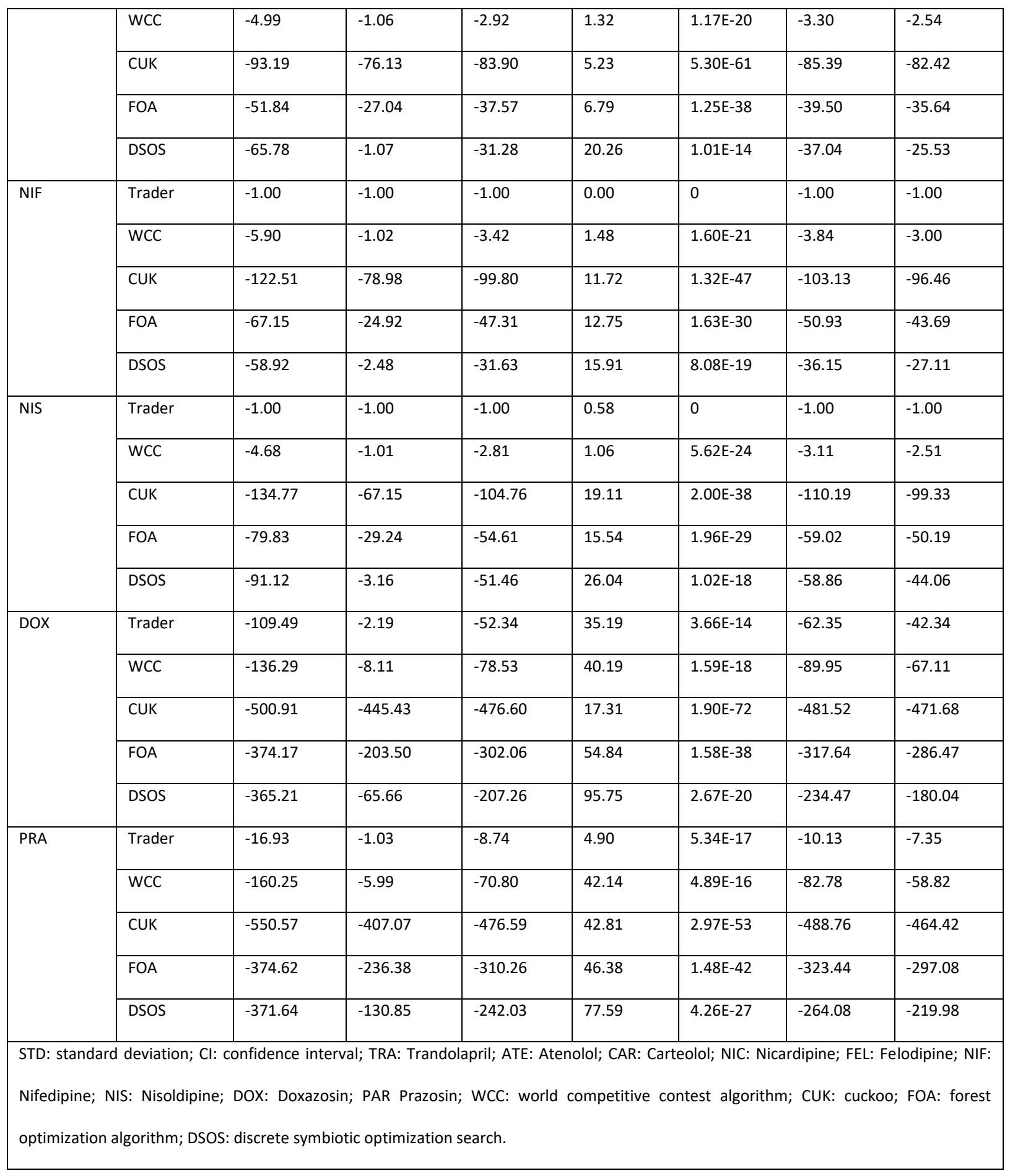


Table 3. A comprehensive comparison of the algorithms' performance on the generated datasets

\begin{tabular}{|l|l|l|l|l|l|l|l|l|}
\hline Dataset & Algorithm & Worst & Best & average & STD & P-value & Low of Cl & High of Cl \\
\hline \multirow{4}{*}{ ALL } & Trader & -15.05 & -1.36 & -7.79 & 4.45 & $4.07 \mathrm{E}-35$ & -9.05 & -6.52 \\
\cline { 2 - 9 } & WCC & -35.34 & -2.47 & -18.23 & 9.61 & $5.45 \mathrm{E}-37$ & -20.96 & -15.49 \\
\cline { 2 - 8 } & CUK & -171.19 & -129.83 & -151.07 & 12.13 & $2.22 \mathrm{E}-39$ & -154.52 & -147.62 \\
\cline { 2 - 9 } & FOA & -112.58 & -60.48 & -88.55 & 16.46 & $8.26 \mathrm{E}-42$ & -93.23 & -83.87 \\
\cline { 2 - 8 } & DSOS & -114.18 & -23.17 & -67.13 & 28.46 & $1.12 \mathrm{E}-35$ & -75.22 & -59.04 \\
\hline
\end{tabular}

STD: standard deviation; Cl: confidence interval; WCC: world competitive contest algorithm; CUK: cuckoo; FOA: forest optimization algorithm; DSOS: discrete symbiotic optimization search.

Table 4. The P-value of the algorithms on the generated datasets based on the results of the Trader algorithm (proposed algorithm) as a test base

\begin{tabular}{|l|l|l|l|l|l|l|l|l|l|}
\hline Algorithm & TRA & ATE & CAR & NIC & FEL & NIF & NIS & DOX & PRA \\
\hline WCC & 1.00 & 1.00 & $9.72 \mathrm{e}-18$ & 0.01 & $1.00 \mathrm{e}-05$ & $1.17 \mathrm{e}-15$ & $2.77 \mathrm{e}-16$ & $3.84 \mathrm{e}-7$ & $1.12 \mathrm{e}-13$ \\
\hline CUK & 1.00 & $3.00 \mathrm{e}-48$ & $2.49 \mathrm{e}-75$ & $4.66 \mathrm{e}-45$ & $1.72 \mathrm{e}-60$ & $2.14 \mathrm{e}-47$ & $3.15 \mathrm{e}-38$ & $4.08 \mathrm{e}-51$ & $1.51 \mathrm{e}-52$ \\
\hline FOA & 1.00 & $4.50 \mathrm{e}-18$ & $6.67 \mathrm{e}-30$ & $1.29 \mathrm{e}-31$ & $1.68 \mathrm{e}-37$ & $4.33 \mathrm{e}-30$ & $4.54 \mathrm{e}-29$ & $3.53 \mathrm{e}-30$ & $6.92 \mathrm{e}-42$ \\
\hline DSOS & 1.00 & $1.01 \mathrm{e}-14$ & $3.99 \mathrm{e}-14$ & $2.87 \mathrm{e}-17$ & $9.73 \mathrm{e}-14$ & $2.84 \mathrm{e}-18$ & $2.19 \mathrm{e}-18$ & $3.45 \mathrm{e}-14$ & $1.44 \mathrm{e}-26$ \\
\hline
\end{tabular}

TRA: Trandolapril; ATE: Atenolol; CAR: Carteolol; NIC: Nicardipine; FEL: Felodipine; NIF: Nifedipine; NIS: Nisoldipine; DOX: Doxazosin; PAR Prazosin; WCC: world competitive contest algorithm; CUK: cuckoo; FOA: forest optimization algorithm; DSOS: discrete symbiotic optimization search. 
Table 5. The synthetic repurposing of drugs for the HT

\begin{tabular}{|c|c|c|c|c|c|}
\hline \multirow[b]{2}{*}{ HT drug } & \multicolumn{5}{|c|}{ The selected drugs by the algorithms } \\
\hline & Trader & WCC & CUK & FOA & DSOS \\
\hline Trandolapril & Cilazapril & Enalapril & Fosinopril & Fosinopril & Quinapril \\
\hline Atenolol & Esmolol & Esmolol & Alprenolol & Nebivolol & Practolol \\
\hline Carteolol & (Xamoterol+Nebivolol) & (Xamoterol+Nebivolol) & Penbutolol & Penbutolol & Penbutolol \\
\hline Nicardipine & $\begin{array}{l}\text { (Cyclandelate+Nisoldipine), } \\
\text { (Drotaverine+Nisoldipine) }\end{array}$ & (Drotaverine+Nisoldipine) & --- & --- & (Drotaverine+Nisoldipine) \\
\hline Felodipine & (Pinaverium+ Nisoldipine) & (Pinaverium+Nilvadipine) & (Pinaverium+Mibefradil) & (Pinaverium+Nifedipine) & (Pinaverium+Nilvadipine) \\
\hline Nifedipine & (Pinaverium + Nisoldipine) & --- & --- & --- & --- \\
\hline Nisoldipine & $\begin{array}{l}\text { (Pinaverium+Isradipine), } \\
\text { (Pinaverium+Drotaverine+Nilvadipine) }\end{array}$ & --- & --- & --- & --- \\
\hline Doxazosin & (Nicergoline) & (Droperidol) & --- & --- & (Dapiprazole) \\
\hline Prazosin & $\begin{array}{l}\text { (Dapiprazole), } \\
\text { (Nicergoline+Tamsulosin), } \\
\text { (Nicergoline+Periciazine+Dapiprazole) }\end{array}$ & (Alfuzosin+Flupentixol) & (Alfuzosin+Flupentixol) & (Alfuzosin+Phentolamine) & (Alfuzosin+Silodosin) \\
\hline $\begin{array}{l}\text { TRA: Trandol } \\
\text { contest algor }\end{array}$ & il; ATE: Atenolol; CAR: Carteolol; NIC: Ni & rdipine; FEL: Felodipine; NI & Nifedipine; NIS: Nisoldipin & DOX: Doxazosin; PAR Prazc & n; WCC: world competitive \\
\hline
\end{tabular}

Table 6. The outcomes of the proposed algorithm on the selected drugs

\begin{tabular}{|c|c|c|c|c|c|}
\hline Given drug & $\begin{array}{l}\text { Chemical } \\
\text { formula }\end{array}$ & Proposed lists & Drugs of the list & Chemical formula & Similarity \\
\hline Trandolapril & $\mathrm{C}_{24} \mathrm{H}_{34} \mathrm{~N}_{2} \mathrm{O}_{5}$ & (Cilazapril) & Cilazapril & $\mathrm{C}_{22} \mathrm{H}_{31} \mathrm{~N}_{3} \mathrm{O}_{5}$ & 0.87 \\
\hline Atenolol & $\mathrm{C}_{14} \mathrm{H}_{22} \mathrm{~N}_{2} \mathrm{O}_{3}$ & (Esmolol) & Esmolol & $\mathrm{C}_{16} \mathrm{H}_{25} \mathrm{NO}_{4}$ & 0.75 \\
\hline \multirow[t]{2}{*}{ Carteolol } & \multirow[t]{2}{*}{$\mathrm{C}_{16} \mathrm{H}_{24} \mathrm{~N}_{2} \mathrm{O}_{3}$} & \multirow[t]{2}{*}{ (Xamoterol+Nebivolol) } & Xamoterol & $\mathrm{C}_{16} \mathrm{H}_{25} \mathrm{~N}_{3} \mathrm{O}_{5}$ & 0.80 \\
\hline & & & Nebivolol & $\mathrm{C}_{22} \mathrm{H}_{25} \mathrm{~F}_{2} \mathrm{NO}_{4}$ & 0.58 \\
\hline \multirow[t]{3}{*}{ Nicardipine } & \multirow[t]{3}{*}{$\mathrm{C}_{26} \mathrm{H}_{29} \mathrm{NO}_{6}$} & \multirow{3}{*}{$\begin{array}{l}\text { (Cyclandelate+Nisoldipine), } \\
\text { (Drotaverine+Nisoldipine) }\end{array}$} & Cyclandelate & $\mathrm{C}_{17} \mathrm{H}_{24} \mathrm{O}_{3}$ & 0.49 \\
\hline & & & Nisoldipine & $\mathrm{C}_{20} \mathrm{H}_{24} \mathrm{~N}_{2} \mathrm{O}_{6}$ & 0.82 \\
\hline & & & Drotaverine & $\mathrm{C}_{24} \mathrm{H}_{31} \mathrm{NO}_{4}$ & 0.71 \\
\hline
\end{tabular}




\begin{tabular}{|c|c|c|c|c|c|}
\hline \multirow[t]{2}{*}{ Felodipine } & \multirow[t]{2}{*}{$\mathrm{C}_{18} \mathrm{HCl}_{2} \mathrm{NO}_{4}$} & \multirow[t]{2}{*}{ (Pinaverium+ Nisoldipine) } & Pinaverium & $\mathrm{C}_{26} \mathrm{H}_{41} \mathrm{BrNO}_{4}$ & 0.35 \\
\hline & & & Nisoldipine & $\mathrm{C}_{20} \mathrm{H}_{24} \mathrm{~N}_{2} \mathrm{O}_{6}$ & 0.57 \\
\hline \multirow[t]{2}{*}{ Nifedipine } & \multirow[t]{2}{*}{$\mathrm{C}_{17} \mathrm{H}_{18} \mathrm{~N}_{2} \mathrm{O}_{6}$} & \multirow[t]{2}{*}{ (Pinaverium + Nisoldipine) } & Pinaverium & $\mathrm{C}_{26} \mathrm{H}_{41} \mathrm{BrNO}_{4}$ & 0.35 \\
\hline & & & Nisoldipine & $\mathrm{C}_{20} \mathrm{H}_{24} \mathrm{~N}_{2} \mathrm{O}_{6}$ & 0.90 \\
\hline \multirow[t]{4}{*}{ Nisoldipine } & \multirow[t]{4}{*}{$\mathrm{C}_{20} \mathrm{H}_{24} \mathrm{~N}_{2} \mathrm{O}_{6}$} & \multirow{4}{*}{$\begin{array}{l}\text { (Pinaverium+Isradipine), } \\
\text { (Pinaverium+Drotaverine+Nilvadipine) }\end{array}$} & Pinaverium & $\mathrm{C}_{26} \mathrm{H}_{41} \mathrm{BrNO}_{4}$ & 0.40 \\
\hline & & & Isradipine & $\mathrm{C}_{19} \mathrm{H}_{21} \mathrm{~N}_{3} \mathrm{O}_{5}$ & 0.83 \\
\hline & & & Drotaverine & $\mathrm{C}_{24} \mathrm{H}_{31} \mathrm{NO}_{4}$ & 0.69 \\
\hline & & & Nilvadipine & $\mathrm{C}_{19} \mathrm{H}_{19} \mathrm{~N}_{3} \mathrm{O}_{6}$ & 0.85 \\
\hline Doxazosin & $\mathrm{C}_{23} \mathrm{H}_{25} \mathrm{~N}_{5} \mathrm{O}_{5}$ & (Nicergoline) & Nicergoline & $\mathrm{C}_{24} \mathrm{H}_{26} \mathrm{BrN}_{3} \mathrm{O}_{3}$ & 0.50 \\
\hline \multirow[t]{5}{*}{ Prazosin } & \multirow[t]{5}{*}{$\mathrm{C}_{19} \mathrm{H}_{21} \mathrm{~N}_{5} \mathrm{O}_{4}$} & \multirow{5}{*}{$\begin{array}{l}\text { (Dapiprazole), } \\
\text { (Nicergoline+Tamsulosin), } \\
\text { (Nicergoline+Periciazine+Dapiprazole) }\end{array}$} & Dapiprazole & $\mathrm{C}_{19} \mathrm{H}_{27} \mathrm{~N}_{5}$ & 0.69 \\
\hline & & & Nicergoline & $\mathrm{C}_{24} \mathrm{H}_{26} \mathrm{BrN}_{3} \mathrm{O}_{3}$ & 0.47 \\
\hline & & & Tamsulosin & $\mathrm{C}_{20} \mathrm{H}_{28} \mathrm{~N}_{2} \mathrm{O}_{5} \mathrm{~S}$ & 0.58 \\
\hline & & & Periciazine & $\mathrm{C}_{21} \mathrm{H}_{23} \mathrm{~N}_{3} \mathrm{OS}$ & 0.53 \\
\hline & & & Dapiprazole & $\mathrm{C}_{19} \mathrm{H}_{27} \mathrm{~N}_{5}$ & 0.69 \\
\hline
\end{tabular}




\section{Figures}
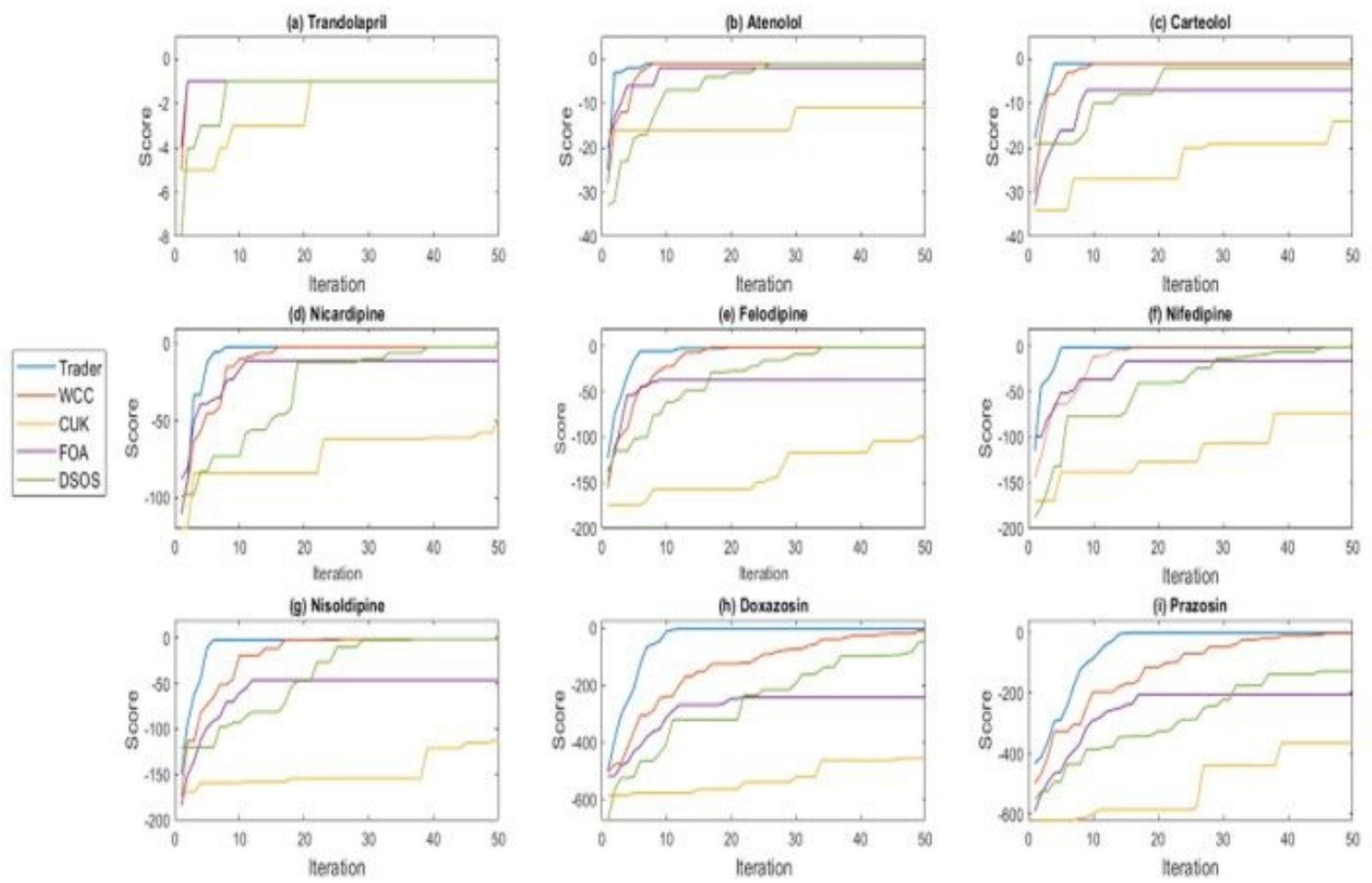

\section{Figure 1}

The convergence behavior of the algorithms on the generated datasets. (a) The convergence of the algorithms on the Trandolapril dataset. (b) The convergence of the algorithms on the Atenolol dataset. (c) The convergence of the algorithms on the Carteolol dataset. (d) The convergence of the algorithms on the Nicardipine dataset. (e) The convergence of the algorithms on the Felodipine dataset. (f) The convergence of the algorithms on the Nifedipine dataset. $(\mathrm{g})$ The convergence of the algorithms on the Nisoldipine dataset. (h) The convergence of the algorithms on the Doxazosin dataset. (i) The convergence of the algorithms on the Prazosin dataset. For the datasets with small sizes, the performance of the algorithms is almost the same. However, through increasing the total number of candidate drugs (the $\mathrm{d}$ CUK, respectively are among the algorithms which are considered to have the proper convergence behavior. 

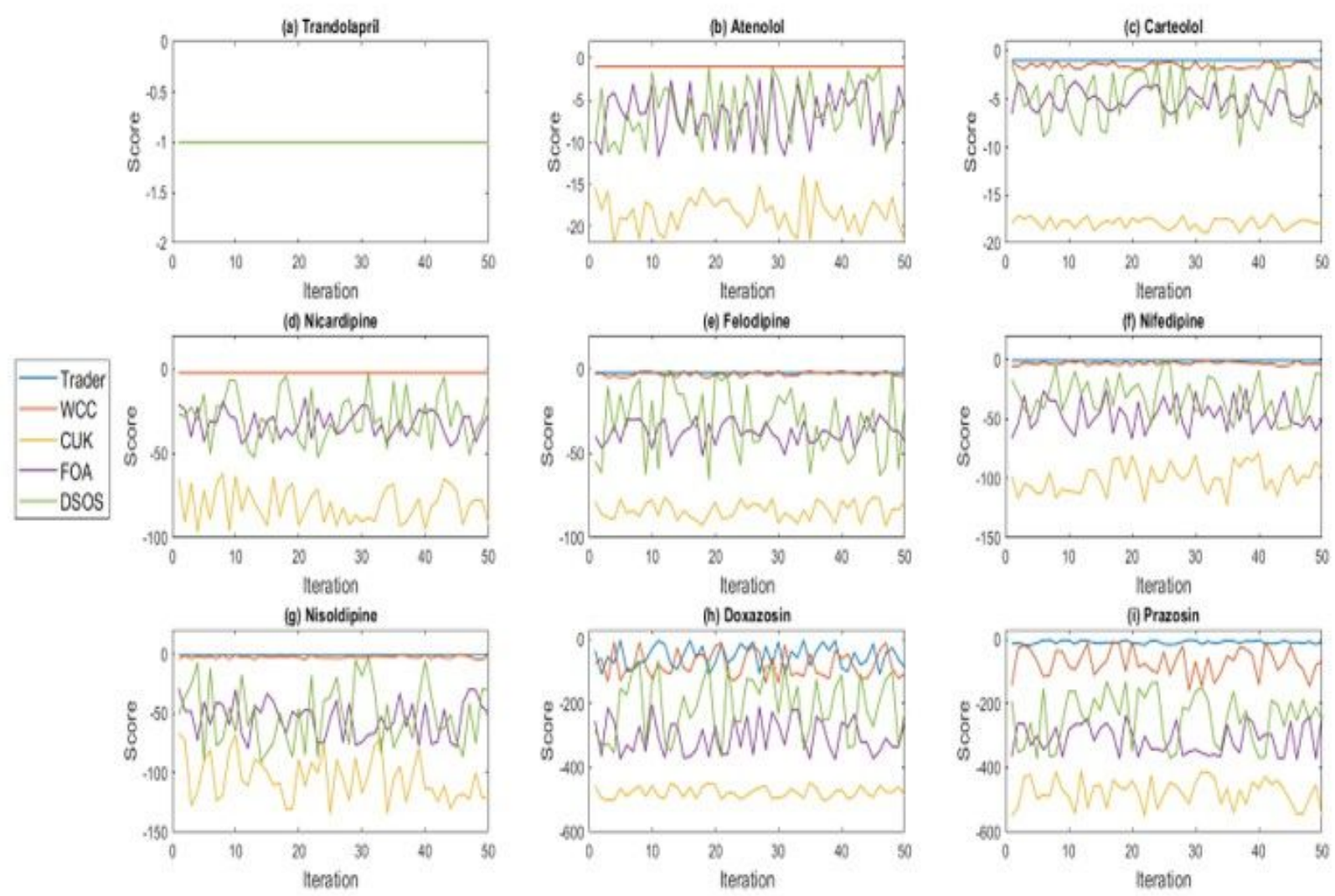

\section{Figure 2}

The stability behavior of the algorithms on the generated dataset. (a) The stability of the algorithms on the Trandolapril dataset. (b) The stability of the algorithms on the Atenolol dataset. (c) The stability of the algorithms on the Carteolol dataset. (d) The stability of the algorithms on the Nicardipine dataset. (e) The stability of the algorithms on the Felodipine dataset. (f) The stability of the algorithms on the Nifedipine dataset. (g) The stability of the algorithms on the Nisoldipine dataset. (h) The stability of the algorithms on the Doxazosin dataset. (i) The stability of the algorithms on the Prazosin dataset. Trader is remarkably more stable than the others and delivers better results on the datasets except for Trandolapril and Nicardipine. Moreover, Trader's performance is better than the others' because the performance of the other algorithms lowers through increasing the total number of candidate drugs. 
Datamining \#1: IF-Then rules

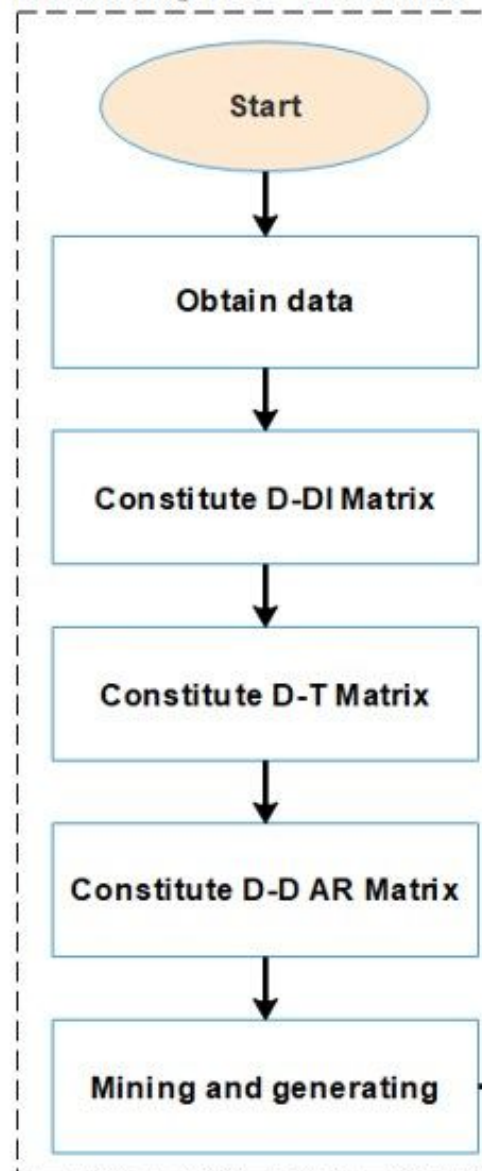

Datamining \#2: Trader Optimi zation Algorithm

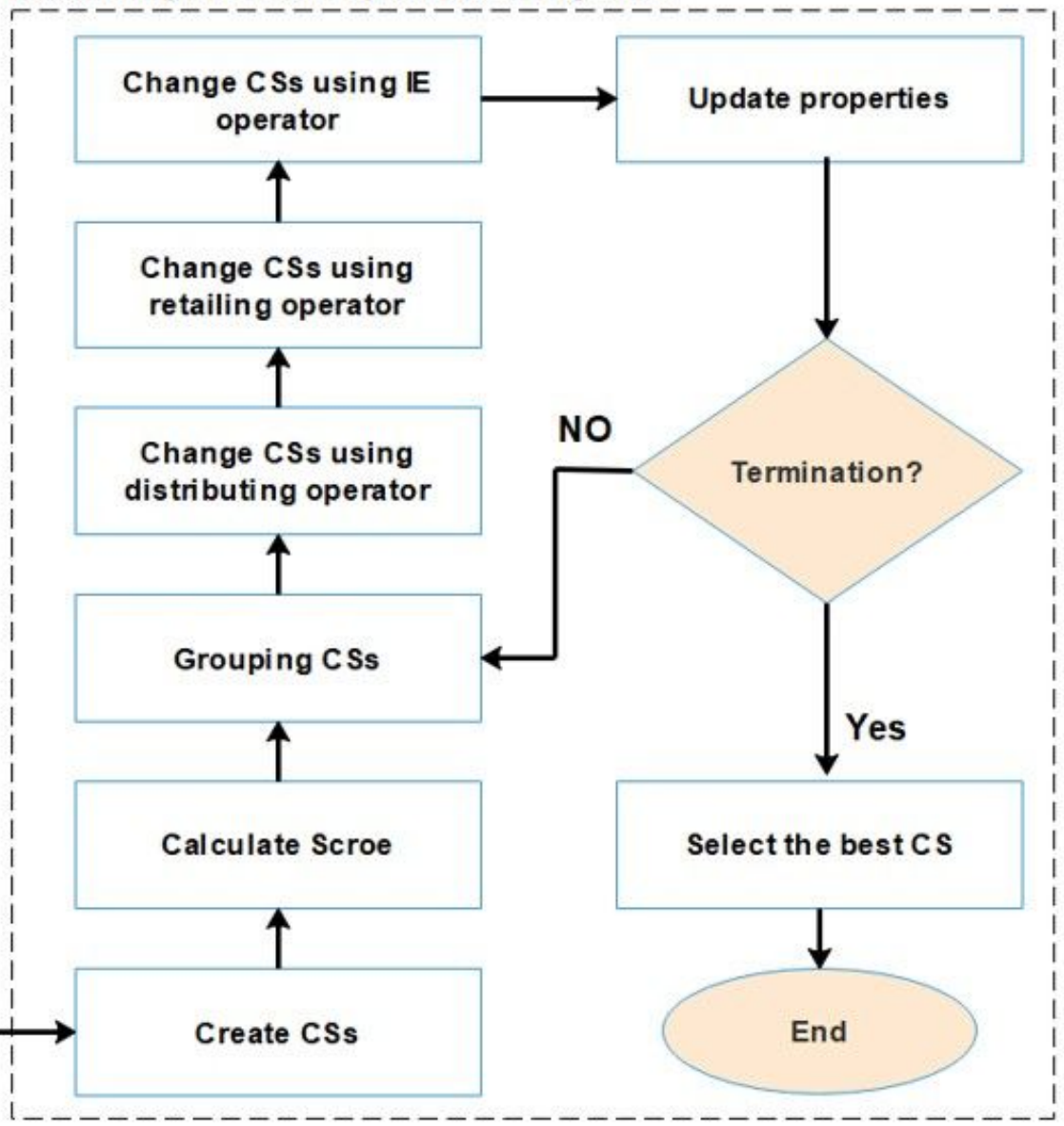

Figure 3

The framework of the proposed method. In the first step, the desired data are obtained from DrugR+ database. Next, drug-disease (D-DI), drug-target (D-T), and drug-drug-adverse reaction (D-D AR) matrices are formed. Drugs which can affect the HT inducing targets, are acquired based on the If-then rules. In the second step, the proposed optimization algorithm (Trader) is used to select a combination of drugs for the repurposing in $\mathrm{HT}$. 


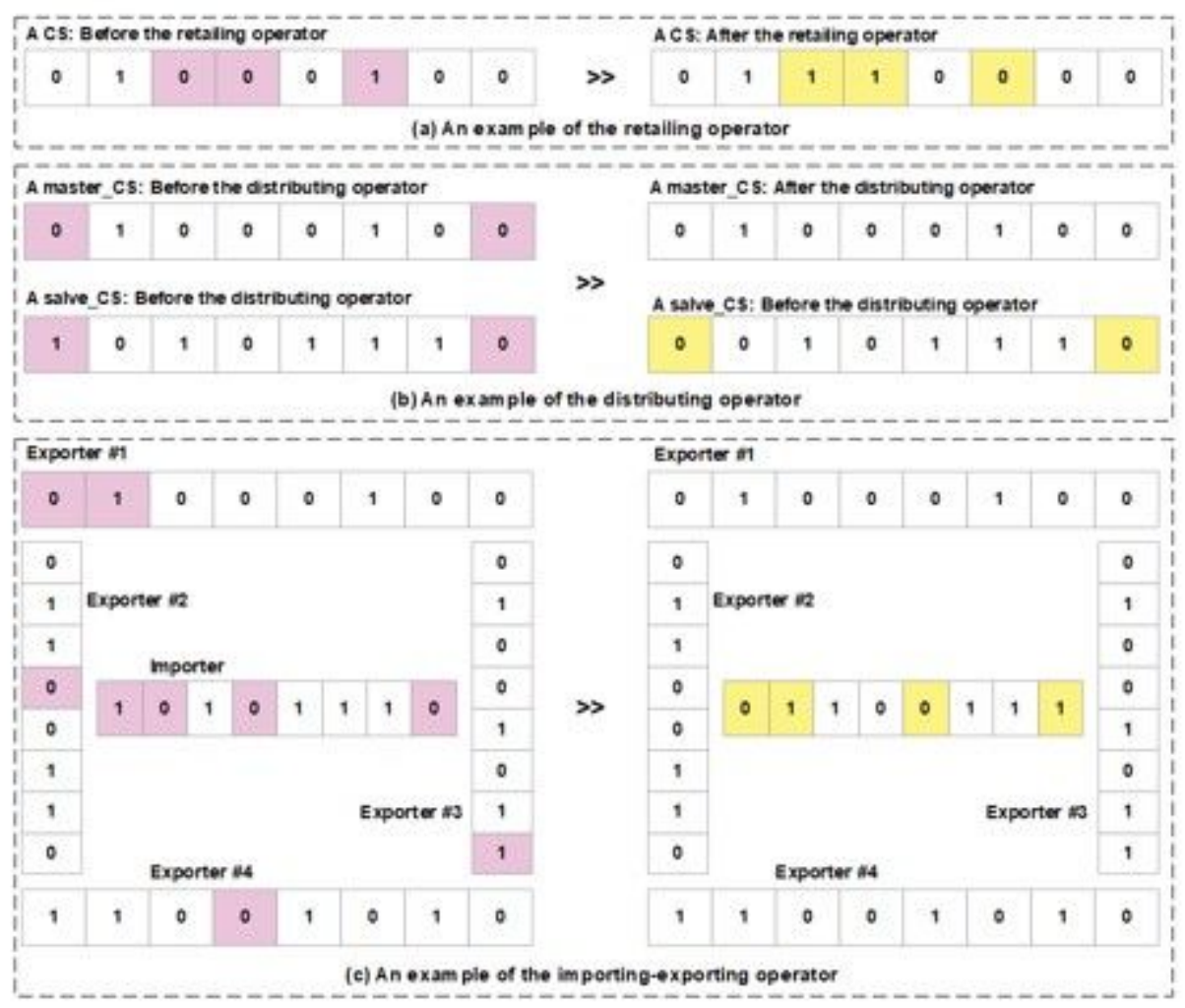

\section{Figure 4}

The Trader's operators. (a) An example of the retailing operator: three points have been chosen randomly, and, then, their values have been updated by Eq. (9). This operator is only applied to slave_CSs. (b) An instance of the distributing operator: The master_CS selects two values from himself and distributes them to the slave_CS. (c) An example of the importing-exporting operator: The exporter CSs select some of their values and send them to the importer CS. After applying the operators, the score function is called. The changes can be accepted, provided that the new score is better than the previous one. In contrast, the changes will be ignored, if the previous values are retrieved from the memory. 